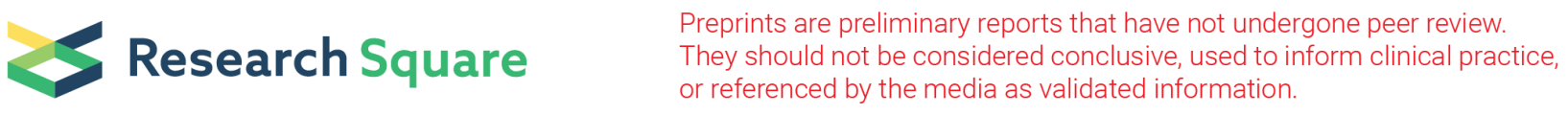

\title{
Genome-Wide Identification, Expression and Potential Function Analysis of the ERF and DREB Subfamily Members in Tomato
}

YuDong Liu ( $\square$ lyd-forever@163.com )

Shihezi University College of Agriculture

Li Zhang

Shenyang Agricultural University

LiJing Chen

Shenyang Agricultural University

ShengQun Pang

Shihezi University College of Agriculture

Qun Zheng

Shihezi University College of Agriculture

ShaoWen Quan

Shihezi University College of Agriculture

YuFeng Liu

Shenyang Agricultural University

Tao Xu

Shenyang Agricultural University

MingFang Qi

Shenyang Agricultural University

Research article

Keywords: AP2/ERF, tomato (Solanum lycopersicum), ERF, DREB, DRE/CRT, GCC, repressor, activator

Posted Date: December 15th, 2020

DOI: https://doi.org/10.21203/rs.3.rs-126159/v1

License: @ (1) This work is licensed under a Creative Commons Attribution 4.0 International License. Read Full License 


\section{Abstract}

Background: APETALA2/ethylene responsive factors (AP2/ERFs) are unique regulators found in the plant kingdom that are involved in all life activity processes, including flowering, fruit ripening, floral meristem growth, and defense responses. In tomato (Solanum lycopersicum), there are 60 DREB and 80 ERF subfamily members, however, their functionality remains poorly understood.

Results: In this work, the AP2 domain conserved amino acid sequences of 68 ERF proteins from 20 plant species were compared and a Multiple Em for Motif Elicitation (MEME) analysis was conducted. Results revealed that the $9^{\text {th }}$ amino acid of the AP2 domain exhibited marked characteristics during the selection of DRE/CRT and/or GCC boxes as protein binding sites. Moreover, motifs near the AP2 domain may be involved in protein binding to DNA, whereas motifs far away from the AP2 domain may function as a part of the transactivation domain. Furthermore, we compared the expression levels of all ERF genes in 30 tomato organs and under biotic and abiotic stresses. Results indicated that most of 17 ERF and DREB repressor genes were highly expressed in almost all tomato organs and under some biotic and abiotic stress. The transcripts per million (TPM) value ratios of all repressor genes exceeded that of all activator genes in 16 tomato organs. Thus, it can be inferred that these repressor genes play vital roles in balancing the regulatory functions of activator genes and activator genes may also conversely compete with repressor genes to ensure normal growth, development, and defense responses in tomato.

Conclusions: This work uncovered the potential functions of all ERF and DREB genes that regulate tomato growth, development, and defense responses, and considers the binding ability of the AP2 domain unique sequences with DRE/CRT and GCC boxes, as well as the relationship of unique motifs with the transactivation domain. These findings will expand upon our understanding of the functions of ERF and DREB genes in tomato.

\section{Background}

Plant hormones are involved in vital processes of complex signal transduction pathways and affect the expression of various genes at different time periods and in different organs, which regulate plant growth, development, and defense responses. To ensure survival and reproduction, diverse hormones, such as auxin (IAA), abscisic acid (ABA), ethylene (ET), gibberellin (GA), cytokinin (CTK), and jasmonate (JA), are synthetized and regulate different life activities in their metabolic networks [1, 2]. In these complex networks, transcription factors (TFs) are critical regulators that play essential roles [3].

Among these TFs, the APETALA2/ethylene responsive factor (AP2/ERF) is widely distributed in the plant kingdom and plays important roles in regulating growth and development. With updates to the plant genome database, more AP2/ERF genes have been identified. Thus far, 147, 291, 170, 163, and 136 AP2/ERF genes have been found in Arabidopsis thaliana [4], Chinese cabbage [5], Salvia miltiorrhiza [6], rice [7] and melon [8], respectively. Currently, RNA sequencing of many species has been conducting, lying an important foundation for the study of AP2/ERF gene families during plant growth and development. Jatropha curcas L. JcERF035 was identified in the roots and leaves under Pi deficiency conditions by RNA sequencing and its overexpression affected root development in Arabidopsis thaliana [9].

AP2/ERF family members have been divided into 5 groups according to Arabidopsis classifications: ERF, DREB, AP2, RAVs and soloist [4, 10]. These subfamilies exhibit different structural characteristics. Among them, differences between ERF and DREB subfamily members is that the 14th and 19th amino acids of the DREB proteins are valine (V) and glutamate (E) in the AP2 domain, but alanine (A) and aspartate (D) in ERF proteins. This difference affects the ability of proteins to interact with DRE or GCC boxes during the regulation of their downstream target genes during transcription [11]. It also suggests that ERF and DREB subfamily members may act in different regulatory pathways. For example, $P U C H$, an ERF subfamily gene, regulates lateral root development, floral meristem identity, and organ initiation in Arabidopsis [12, 13]. Arabidopsis DREB2A overexpression enhanced drought and heat tolerance in transgenic plants [14, 15]. Additionally, DREB2A affected leaf senescence by interacting with radical-induced cell death 1 (RCD1) under heat stress [16]. Thus, an ERF protein is often involved in several regulatory networks, which cause some ERF proteins to exert the same or opposite function during different processes. AtERF1 activates the defense-related gene, PDF1.2 [17], while AtERF4 represses PDF1.2 in biotic stress tolerance [18]. Moreover, AtERF2 and AtERF5 are activators and AtERF3 is a repressor, which regulate downstream target genes during transcript in defense responses [19].

Although different ERFs may exhibit opposing functions in different vital processes, an ERF may function in several of these processes. For example, AtDREB1A in transgenic Arabidopsis plants resulted in the dwarfed phenotypes and freezing and dehydration tolerance, whereas AtDREB2A transgenic plants exhibited slight growth retardation [20]. Additionally, the wild-type Arabidopsis plants overexpressing AtERF53 exhibited unstable drought tolerance, while $\mathrm{rg} / \mathrm{g} 1 \mathrm{rg} / \mathrm{g} 2$ double mutant plants overexpressing AtERF53 exhibited stable drought tolerance, as RGLG1 and RGLG2 together negatively regulate AtERF53 transcription [21]. However, AtERF7 overexpression decreased the sensitivity of guard cells to $A B A$ and increased water loss during transpiration, which reduced drought tolerance in transgenic plants. Contrasting results were found in AtERF7RNA interference plants [22]. These studies suggest that although the regulatory pathways of DREB and ERF proteins differ, they can achieve the same effects in different vital processes. 
Solanum lycopersicum (tomato), as an important fruit vegetable, is widely planted in many countries. Tomato fruit is abundantly nutrition and has a unique flavor, and can be eaten raw, boiled, or processed into ketchup or juice. Thus, improving the fruit yield and quality of tomato is the primary goal of tomato production. To achieve this goal, our understanding of the underlying molecular mechanisms of different vital processes must be enhanced, including seed germination, fruit ripening and softening, flower development, and defense responses to biotic and abiotic stresses. Among these processes, ERFs as regulators or repressors play important roles that affect different gene networks. In this study, we identified, corrected, and analyzed all ERF and DREB subfamily members based on S. lycopersicum genome database versions 2.0, 3.2, and 4.0. To understand the potential functions of ERF and DREB subfamily members, several RNA sequencing databases were used to analyze gene expression levels during vital processes, including growth, development, and defense responses to biotic and abiotic stresses. These works will help establish the regulatory networks of ERF and DREB subfamilies and uncover effective ways to improve tomato yield and quality.

\section{Methods}

\section{Identification of ERF and DREB subfamily members in tomato}

The genome sequences of S. lycopersicum were downloaded from a database of gene annotations, SGN, (Release v4.0 and v3.2, http://solgenomics.net/organism/solanum_lycopersicum/genome). The hidden Markov model (HMM) profile of the AP2 domain (PF00847) was downloaded from the Pfam database (http://pfam.xfam.org/). HMMER v3.3 was used to search for candidate AP2/ERF genes from the tomato genome database. The default parameters were used and the cutoff value was set to 0.001 . All of the candidate AP2/ERF proteins with only a single AP2 domain were selected as candidate ERF proteins. The Pfam, SMART (http://smart.embl-heidelberg.de/), and NCBI CDD databases (https://www.ncbi.nlm.nih.gov/cdd) were used to validate the candidate ERF proteins. Finally, the identification results of the 3 genome versions (2.0,3.2, and 4.0) and NCBI database were compared to determine the final ERF subfamily members of S. Iycopersicum.

\section{Phylogenetic analysis}

Multiple sequence alignments of the tomato ERF proteins were performed using CLUSTAL W based on the complete sequences. To understand the relationship among the tomato ERF proteins, a phylogenetic tree was inferred using the maximum likelihood method based on the Whelan and Goldman model [23] of MEGA v7.0 with the following parameters: JTT + G model, partial deletion with $80 \%$ site coverage cutoff, and 1000 bootstrap replications [24].

\section{Gene structure and conserved motif analyses}

According to the cluster analysis results of the tomato ERF gene subfamily, the structural domain analysis of the ERF protein sequences of different groups was conducted using Jalview software [25]. Homologous alignments were compared using T-Coffee software [26]. The protein sequences of non-conservative regions were deleted. The alignment results were preserved in EPS format. Conserved motifs of the tomato ERF subfamily proteins were identified using the Multiple Em for Motif Elicitation (MEME) online tool v5.1.1 (http://meme-suite. org/tools/meme) with the following parameters: number of occurrences of a single motif distributed among the sequences within the model, 0 or 1 per sequence; maximum number of motifs, 20; optimum width of each motif, 6-50 residues.

\section{Transcriptome data sources and bioinformation analysis}

Transcriptome sequencing data were downloaded from the NCBI SRA database (https://www.ncbi.nlm.nih.gov/sra/) using the SRA toolkit. The project number of transcriptome data used in this article is as follows: PRJNA507622 (S. lycopersicum, 30 tomato organs) [27], PRJNA560638 (cultivated tomato, S. lycopersicum, heat, leaf), PRJNA484882 (Jinlingmeiyu, S. lycopersicum, drought, leaf), PRJNA312788 (Moneymaker, S. lycopersicum, low temperature, leaf), PRJDB1863 (S. lycopersicum, LED red light, leaf) [28], PRJNA530354 (Jinpeng No.1, S. lycopersicum, strong light, leaf), PRJNA434798 (Moneymaker, S. lycopersicum, TYLCSV, leaf) [29], PRJNA413551 (SW-7 and Fla. 8059, S. lycopersicum, TSWV, leaf), PRJNA407898 (Moneymaker and Motelle, S. lycopersicum, F. oxysporum, root), PRJNA531929 (S. lycopersicum, tomato psyllid, leaf) [30], and PRJNA565137 (M82, S. lycopersicum, STV, leaf) [31].

The transcripts per million (TPM) expression values of the transcriptomes of different organs, biotic and abiotic stressors of tomato were obtained using the SRA toolkit and Salmon software [32]. Subsequently, the TPM values were processed to quantify of gene expression levels of the original data. The expression heat map of the ERF genes in different organs, and biotic and abiotic stressors of tomato were drawn using R-pheatmap based on the TPM values.

\section{Results}

\section{Sequence correction of ERF and DREB subfamily genes}

To ensure the sequence accuracy of all AP2/ERF genes, the Pfam model (pf00847) of the AP2 domain downloaded from the Pfam website was used to search the tomato v4.0 protein database. A total of 166 AP2/ERF proteins with an AP2 domain E-value $<0.001$ were obtained. Among 
these proteins, 20 had $\geq 2$ AP2 domains, while 146 proteins had single AP2 domain. Among the latter, 3 proteins with the B3 domain were RAVtype AP2/ERF proteins. Thus, there were 143 ERF subfamily proteins with a single AP2 domain. The 143 protein sequences were submitted to the Pfam, CDD, and smart websites for conservative domain analysis. Subsequently, 140 tomato ERF subunit genes with a single AP2 domain were identified. The sequences of these genes were compared in 3 tomato genome sequencing DNA, CDS, cDNA, and protein databases (versions 2.0, 3.2, and 4.0); 26 genes were found to be different (Table S1). The CDS and protein sequences of these 26 genes were compared and confirmed according to the tomato genome and NCBI databases (Tables S2 and S3). Finally, the corrected protein sequences were used for subsequent analyses (Tables S2).

\section{Characteristics, polarity, and chemical structure analysis of the 14th and 19th amino acids in the AP2 domain}

Among the 140 ERF genes with a single AP2 domain, the 14th amino acid of the AP2 domain was $V$ in 57 genes. Among these 57 genes, the 19th amino acid of the AP2 domain was glutamic acid (E) in 30 genes, aspartic acid (D) in 4 genes, ssparagine (N) in 1 gene, glutamine (Q) in 4 genes, histidine $(\mathrm{H})$ in 6 genes, leucine $(\mathrm{L})$ in 10 genes, alanine $(\mathrm{A})$ in 1 gene, and $\mathrm{V}$ in 1 gene (Tables 1 and S4). These 57 genes were identified as DREB genes. Additionally, the 14th and 19th amino acids of the AP2 domain were isoleucine (I) and D, respectively, in SIERF2-5, SIERF10-6, and SIERF10-8. The codon of I was AUA/AUC, GUA/GUG/GUU/GUC for V, but GCA/GCG/GCU/GCC for A. The characteristics, polarity, and chemical structure of I and $V$ were hydrophobic, nonpolar, and aliphatic, while A was neutral, nonpolar, and aliphatic (Tables 1 and S4). Thus, I can only be a V mutation. Accordingly, the 3 genes were identified as DREB genes. In the 19th amino acid of the AP2 domain, the hydrophilic amino acids included $E, D, N, Q$, and $H$, the hydrophobic amino acids included $L$ and $V$, and the neutral amino acids included $A$. The negative charged amino acids ( $E$ and $\mathrm{D}$ ), uncharged amino acids ( $\mathrm{N}$ and $\mathrm{Q}$ ), and positively charged amino acids (H) were polar; the nonpolar amino acids included L, A, and V. Additionally, $\mathrm{H}$ had a heterocycle chemical structure, while the others were aliphatic (Table 1$)$. These differences may affect the functionality of DREB protein interactions with DRE and GCC boxes.

Table 1

The 14th /19th amino acid analysis of the DREB subfamily AP2 domain

\begin{tabular}{|c|c|c|c|c|c|c|c|c|c|}
\hline $\begin{array}{l}\text { Gene } \\
\text { number }\end{array}$ & 14th & 19th & $\begin{array}{l}\text { 14th } \\
\text { codon }\end{array}$ & $\begin{array}{l}\text { 19th } \\
\text { codon }\end{array}$ & 14th /19th Characters & $\begin{array}{l}\text { 14th } \\
\text { polarity }\end{array}$ & $\begin{array}{l}\text { 14th } \\
\text { chemical } \\
\text { structure }\end{array}$ & $\begin{array}{l}\text { 19th } \\
\text { polarity }\end{array}$ & $\begin{array}{l}\text { 19th } \\
\text { chemical } \\
\text { structure }\end{array}$ \\
\hline 30 & V & $\mathrm{E}$ & $\begin{array}{l}\text { GUA/GUG/ } \\
\text { GUU/GUC }\end{array}$ & $\begin{array}{l}\text { GAA/ } \\
\text { GAG }\end{array}$ & Hydrophobic/Hydrophilic & Nonpolarity & Aliphatic & $\begin{array}{l}\text { Polarity } \\
\text { with } \\
\text { negative } \\
\text { charge }\end{array}$ & Aliphatic \\
\hline 4 & V & D & GUU & $\begin{array}{l}\text { GAU/ } \\
\text { GAC }\end{array}$ & Hydrophobic/Hydrophilic & Nonpolarity & Aliphatic & $\begin{array}{l}\text { Polarity } \\
\text { with } \\
\text { negative } \\
\text { charge }\end{array}$ & Aliphatic \\
\hline 1 & V & $\mathrm{N}$ & GUU & AAC & Hydrophobic/Hydrophilic & Nonpolarity & Aliphatic & $\begin{array}{l}\text { Polarity, } \\
\text { without } \\
\text { charge }\end{array}$ & Aliphatic \\
\hline 4 & V & Q & $\begin{array}{l}\text { GUA/GUG/ } \\
\text { GUU }\end{array}$ & CAA & Hydrophobic/Hydrophilic & Nonpolarity & Aliphatic & $\begin{array}{l}\text { Polarity } \\
\text { without } \\
\text { charge }\end{array}$ & Aliphatic \\
\hline 6 & V & $\mathrm{H}$ & $\begin{array}{l}\text { GUU/ } \\
\text { GUC }\end{array}$ & $\begin{array}{l}\text { CAU/ } \\
\text { CAC }\end{array}$ & Hydrophobic/Hydrophilic & Nonpolarity & Aliphatic & $\begin{array}{l}\text { Polarity } \\
\text { with } \\
\text { positive } \\
\text { charge }\end{array}$ & Heterocycle \\
\hline 10 & V & $\mathrm{L}$ & $\begin{array}{l}\text { GUA/GUG/ } \\
\text { GUU/GUC }\end{array}$ & $\begin{array}{l}\text { UUG/CUU/ } \\
\text { CUA/UUA }\end{array}$ & Hydrophobic/Hydrophobic & Nonpolarity & Aliphatic & Nonpolarity & Aliphatic \\
\hline 1 & V & A & GUA & GCA & Hydrophobic/Neutral & Nonpolarity & Aliphatic & Nonpolarity & Aliphatic \\
\hline 1 & V & V & GUG & GUU & Hydrophobic/Hydrophobic & Nonpolarity & Aliphatic & Nonpolarity & Aliphatic \\
\hline 2 & I & $\mathrm{D}$ & AUA & GAC & Hydrophobic/Hydrophilic & Nonpolarity & Aliphatic & $\begin{array}{l}\text { Polarity } \\
\text { with } \\
\text { negative } \\
\text { charge }\end{array}$ & Aliphatic \\
\hline 1 & I & V & AUC & GUU & Hydrophobic/Hydrophobic & Nonpolarity & Aliphatic & Nonpolarity & Aliphatic \\
\hline
\end{tabular}

Among the 80 ERF subfamily members, the 14th and 19th amino acids of the AP2 domain were A and D in 70 genes. Additionally, there was an $A$ and tyrosine $(Y)$ in 1 gene, $A$ and $N$ in 1 gene, threonine $(T)$ and $D$ in 1 gene, serine $(S)$ and $D$ in 4 genes, $E$ and $D$ in 1 gene, glycine (G) and $N$ in 2 genes, and I and $V$ in 1 gene (Tables 2 and S5). In the 14th amino acid of the AP2 domain, the neutral amino acids included A, T, S, and G, and 
the hydrophilic amino acid included $\mathrm{E}$. The nonpolar amino acid was $\mathrm{A}$, the polar amino acids without charges were T, S, and $\mathrm{G}$, and the chemical structure of these amino acids is aliphatic. In the 19th amino acid of the AP2 domain, D, Y, and N comprised the hydrophilic amino acids, the negative charged amino acids (D), the uncharged amino acids ( $\mathrm{Y}$ and $\mathrm{N}$ ) were polar, and the chemical structure of these amino acids was aliphatic (Table 2). Thus, the 80 genes with a single AP2 domain were identified as ERF subfamily members. These differences may affect the functionality of ERF protein interactions with GCC boxes.

Table 2

The 14th /19th amino acid analysis of the ERF subfamily AP2 domain

\begin{tabular}{|c|c|c|c|c|c|c|c|c|c|}
\hline $\begin{array}{l}\text { Gene } \\
\text { number }\end{array}$ & 14th & 19th & $\begin{array}{l}\text { 14th } \\
\text { codon }\end{array}$ & $\begin{array}{l}\text { 19th } \\
\text { codon }\end{array}$ & Characters & 14th polarity & $\begin{array}{l}\text { 14th } \\
\text { chemical } \\
\text { structure }\end{array}$ & 19th polarity & $\begin{array}{l}\text { 19th } \\
\text { chemical } \\
\text { structure }\end{array}$ \\
\hline 70 & A & $\mathrm{D}$ & $\begin{array}{l}\text { GCA/GCG/ } \\
\text { GCU/GCC }\end{array}$ & GAU/GAC & Neutral/Hydrophilic & Nonpolarity & Aliphatic & $\begin{array}{l}\text { Polarity with } \\
\text { negative } \\
\text { charge }\end{array}$ & Aliphatic \\
\hline 1 & A & Y & GCA & UAU & Neutral/Hydrophilic & Nonpolarity & Aliphatic & $\begin{array}{l}\text { Polarity } \\
\text { without } \\
\text { charge }\end{array}$ & Aromatic \\
\hline 1 & A & $\mathrm{N}$ & $\mathrm{GCU}$ & AAU & Neutral/Hydrophilic & Nonpolarity & Aliphatic & $\begin{array}{l}\text { Polarity } \\
\text { without } \\
\text { charge }\end{array}$ & Aliphatic \\
\hline 1 & $\mathrm{~T}$ & $\mathrm{D}$ & ACG & GAU & Neutral/Hydrophilic & $\begin{array}{l}\text { Polarity } \\
\text { without } \\
\text { charge }\end{array}$ & Aliphatic & $\begin{array}{l}\text { Polarity with } \\
\text { negative } \\
\text { charge }\end{array}$ & Aliphatic \\
\hline 4 & $S$ & $\mathrm{D}$ & UCU/ UCA & GAU/GAC & Neutral/Hydrophilic & $\begin{array}{l}\text { Polarity } \\
\text { without } \\
\text { charge }\end{array}$ & Aliphatic & $\begin{array}{l}\text { Polarity with } \\
\text { negative } \\
\text { charge }\end{array}$ & Aliphatic \\
\hline 1 & $\mathrm{E}$ & $\mathrm{D}$ & GAA & GAU & Hydrophilic/Hydrophilic & $\begin{array}{l}\text { Polarity with } \\
\text { negative } \\
\text { charge }\end{array}$ & Aliphatic & $\begin{array}{l}\text { Polarity with } \\
\text { negative } \\
\text { charge }\end{array}$ & Aliphatic \\
\hline 2 & G & $\mathrm{N}$ & GGA & AAC & Neutral/Hydrophilic & $\begin{array}{l}\text { Polarity } \\
\text { without } \\
\text { charge }\end{array}$ & Aliphatic & $\begin{array}{l}\text { Polarity } \\
\text { without } \\
\text { charge }\end{array}$ & Aliphatic \\
\hline
\end{tabular}

\section{Phylogenetic analysis of ERF and DREB proteins}

To understand their genetic relationships, the protein sequences of the 60 DREB and 80 ERF subfamily members were classified into 6 groups (Fig. 1). The I group included 51 DREB proteins. Among these proteins, 37 and 14 proteins differentiated into the I-A and I-B subgroups, respectively. The I-A subgroup included 30 proteins with V14E19, 3 proteins with V14Q19 (SIERF12-9, SIERF1-13, and SIERF7-1), 1 protein with V14A19 (SIERF11-4), 1 protein with V14V19 (SIERF1-5), and 2 proteins with V14L19 (SIERF6-5 and SIERF12-3) (Table S4). Seven CBF proteins (SIERF3-7, SIERF3-22, SIERF3-6, SIERF8-2, SIERF8-3, SIERF12-11, and SIERF1-3) clustered together and were in the I-A subgroup (Fig. 1). Additionally, the I-A subgroup included 4 repressor proteins (SIERF9-1, SIERF2-10, SIERF4-10, and SIERF4-11) with EAR motif (DLNxxP or LxLxL) (Table S4). However, the I-B subgroup only included 6 proteins with V14H19 and 8 proteins with V14L19. SIERF9-10 and SIERF8-14 were repressor proteins in the I-B subgroup (Fig. 1; Table S4).

Group II included 49 ERF subfamily proteins. Among these proteins, 14 and 35 proteins differentiated into the II-A and II-B subgroups, respectively (Fig. 1). All members of the II-A subgroup belonged to ERF proteins with A14D19. In the II-B subgroup, there were 33 proteins with A14D19, 1 protein with T14D19 (SIERF1-10), and 1 protein with S14D19 (SIERF1-11) (Table S5). In the II-B subgroup, 6 proteins with the EDLL transactivation motif (ExxxxDxxxLxxxL) clustered together (SIERF3-1, SIERF9-7, SIERF9-3, SIERF9-4, SIERF3-2, and SIERF9-8) (Fig. 1). SIERF5-8 was also a repressor protein in the II-B subgroup. Groups III and IV included 13 and 16 ERF subfamily proteins, respectively. However, group III also included a DREB protein with V14D19 (SIERF1-4) that clustered with an ERF-type protein (SIERF1-2). One protein with S14D19 (SIERF1-15) and 1 repressor protein (SIERF4-1) were clustered into group III. Among these proteins in group IV, there were 2 proteins with S14D19 (SIERF3-16 and SIERF12-1), 2 proteins with G14N19 (SIERF12-6 and SIERF12-7), and all others belonged to proteins with A14D19. Additionally, 9 repressor proteins (SIERF10-1, SIERF7-5, SIERF12-1, SIERF7-2, SIERF2-6, SIERF7-3, SIERF10-2, SIERF3-4, and SIERF3-16) were in group IV (Fig. 1; Table S5). Group V had 8 DREB proteins, including 3 proteins with V14D19, 1 protein with V14Q19, 1 protein with V14N19, 2 proteins with I14D19, and 1 protein with I14V19 (Fig. 1; Table S4). Group VI included 1 protein with E14D19 (SIERF2-1) and 1 protein with A14D19 (SIERF9-2) (Table S5).

\section{Motif analysis of ERF and DREB protein sequences}

To understand the constructional characteristics of ERF and DREB proteins, a Multiple Em for Motif Elicitation (MEME) analysis was conducted to calculate the possible motifs of the 140 proteins. $\beta 1$ of the AP2 domain was located on the left of motif $2, \beta 2$ was located on the right of 
motif 2 and left of motif 3, and $\beta 3$ and a were located on motif 1. All 140 proteins, except SIERF9-1, SIERF10-9, SIERF6-1, SIERF8-4, SIERF8-12, SIERF3-8, SIERF2-1, and SIERF9-2, had motifs 1, 2, and 3. SIERF9-1, SIERF10-9, SIERF6-1, SIERF8-4, and SIERF8-12 had only motifs 1 and 3, as well as a same sequence to motif 25 in front of motif 3. SIERF3-8 had motifs 2, 3, and 16. Motif 16 had a similar sequence as motif 1 . SIERF2-1 and SIERF9-2 did not have motif 1, 2 and 3, but had a similar sequence as motif 16 with motif 1 (Fig. 2). These results suggest that SIERF9-1, SIERF10-9, SIERF6-1, SIERF8-4, SIERF8-12, SIERF3-8, SIERF2-1, and SIERF9-2 may have the low ability to bind with GCC or DRE boxes.

In addition to motifs $1,2,3,16$, and 25, some motifs were located on both sides of the AP2 domain of many ERF and DREB proteins. For example, motifs 10 and 20 were near the left of the AP2 domain in 7 CBF and SIERF1-13, respectively, while motifs 4 and 5 were near the right of motif 1 and especially motif 4 (Fig. 2). These findings suggest that motifs 4, 5, 10, and 20 may be involved in the process of AP2 domain binding with GCC or DRE boxes. However, motifs $6-9,11-15,17-19,21,23$, and 24 were relatively far away from the AP2 domain, may be located in the transactivation or repression domains, and may be involved in regulating the expression of their downstream target genes. However, some ERF and DREB proteins, including SIERF4-10, SIERF7-1, SIERF10-5, SIERF6-7, SIERF3-15, SIERF6-9, SIERF3-16, SIERF12-6, SIERF12-7, SIERF3-4, SIERF7-3, SIERF2-6, SIERF3-13, and SIERF2-5, did not have other motifs, except motifs 1, 2, 3, and 4 (Fig. 2). Nevertheless, a few of these proteins had a typical EAR (LxLxL or DLNxxP) repression domain, including SIERF4-10, SIERF3-16, SIERF3-4, SIERF7-3, and SIERF2-6. These proteins bound to DNA with the AP2 domain and repressed the expression of downstream target genes with the EAR domain. However, SIERF7-1, SIERF10-5, SIERF6-7, SIERF3-15, SIERF6-9, SIERF12-6, SIERF12-7, SIERF3-13, and SIERF2-5 especially protein sequences with $<100$ amino acids (SIERF12-6 and SIERF12-7) may competitively inhibit other ERF and DREB proteins (Fig. 2).

\section{Unique amino acids affected the ability of protein to bind with DRE and GCC boxes}

Previous studies found that some DREB and ERF subfamily proteins only bound to DRE or GCC boxes, but most of these proteins can also interact with these boxes. However, the correlation between the characteristics and binding ability of DREB and/or ERF subfamily proteins remains unclear. To distinguish the difference between DREB and ERF proteins during binding with DRE or GCC boxes, the AP2 domain amino acid sequences of 49 Arabidopsis and 19 other species ERF proteins, including 8 tomato ERF proteins, were compared. The binding assays of the 68 ERF proteins with DRE and GCC boxes were completed through an electrophoretic mobility shift assay (EMSA), yeast one-hybrid, or proteome chip assays. Among these proteins, there were 42 protein AP2 domains that included P9, 5 included H9, 5 included S9, 6 included N9, 3 included Q9, 2 included K9, 2 included T9, and 1 included I9 (Fig. 3). Only 19 proteins bound with GCC box, including 17 ERF with P9, 2 DREB with 1 P9 and $1 \mathrm{H} 9$. Additionally, 37 proteins bound with DRE and GCC boxes, including 23 ERF with P9, 14 DREB with 1 P9, 4 H9, 4 N9, 2 Q9, 1 T9, 1 K9, and 1 19. Only 12 proteins bound with DRE, including 1 ERF with P9, 11 DREB with 5 S9, 2 N9, 2 K9, 1 Q9, and 1 T9 (Fig. 3). These results suggest that almost all ERFs with P9 and H9 can interact with GCC box, and most can also bind with DRE. All DREB with S9 can only interact with DRE, but other DREBs with N9, K9, Q9, T9, and 19 may only bind with DRE or with DRE and GCC boxes. The A14 and A15 amino acids of ERF AP2 domain were conserved, but the 13th amino acid may be Y, F, or W. The W13 and V14 amino acids of the DREB AP2 domain were conserved, but the 15th amino acid may be S, A, or C (Fig. 3). These characteristics of ERFs and DREBs may affect the ability of proteins to bind with DRE and GCC boxes.

In tomato DREB subfamily members, there are 10 DREBs with S9W13V14S15 (SIERF3-20, SIERF5-5, SIERF6-8, SIERF8-10, SIERF8-11, SIERF812, SIERF9-1, SIERF10-9, SIERF11-4, and SIERF12-9) and 1 DREB with S9W13V14C15 (SIERF8-4) (Table S1), which suggests that these 11 DREBs may only bind with DRE. There was 1 DREB with S9W13I14A15 (SIERF10-6). However, the ability of this protein to bind with DRE and GCC boxes has not been determined. There were 4 DREBs with H9W13V14S15 (SIERF12-4, SIERF6-7, SIERF3-15, and SIERF6-9) and 9 DREB with H9W13V14A15 (SIERF3-14, SIERF9-10, SIERF8-5, SIERF8-14, SIERF4-6, SIERF12-13, SIERF4-9, SIERF7-4, and SIERF12-5) (Table S1). DREB with H9W13V14A15 can interact with GCC or both DRE and GCC boxes. Seven CBF proteins exist in tomato DREB subfamily members, including 5 CBF with N9W13V14C15 (SIERF3-7, SIERF3-22, SIERF3-6, SIERF8-2, and SIERF1-3) and 2 CBF with D9W13V14C15 (SIERF8-3 and SIERF12-11). There were 3 DREB with N9W13V14S15 (SIERF6-1, SIERF8-6, and SIERF1-13), 5 DREB with K9W13V14S15 (SIERF11-5, SIERF11-6, SIERF1-5, SIERF6-5, and SIERF12-3), 4 DREB with K9W13V14A15 (SIERF2-10, SIERF4-10, SIERF7-1, and SIERF1-4), 6 DREB with T9W13V14A15 (SIERF10-4, SIERF10-5, SIERF10-7, SIERF4-4, SIERF4-11, and SIERF5-11), 3 DREB with 1 Q9W13V14S15 (SIERF6-4), 1 I9W13V14A15 (SIERF6-2), and 1 A9W13V14S15 (SIERF12-2), 5 DREB with P9W13V14A15 (SIERF2-2, SIERF1-1, SIERF3-13, SIERF1-14, and SIERF3-19), and 1 DREB with P9W13I14A15 (SIERF10-8) (Table S1). These DREB proteins may interact with DRE, some of which may also bind with GCC boxes.

In tomato ERF subfamily members, there were ERFs with 22 P9Y13A14A15, 21 P9F13A14A15, and 21 P9W13A14A15 (Table S1). There were ERFs with K9Y13A14A15 (SIERF3-18), P9Y13A14S15 (SIERF5-7), P9Y13G14A15 (SIERF12-7), P9Y13G14V15 (SIERF12-6), T9F13A14A15 (SIERF3-2), K9F13A14T15 (SIERF5-1), Q9F13S14A15 (SIERF1-11), P9F13S14A15 (SIERF12-1), Q9F13T14A15 (SIERF1-10), E9W13A14A15 (SIERF1-2), 2 with K9W13A14A15 (SIERF4-1 and SIERF5-2), and 2 with P9W13S14A15 (SIERF1-15 and SIERF3-16) (Table S1). This indicates that P9A14A15 of the ERF AP2 domain may play an important role in binding with GCC box. However, it has not been determined why most ERF proteins can also interact with DRE in comparison with these ERF proteins that only bind with GCC boxes.

\section{Expression analysis of CBF genes in tomato}


To understand the function of different ERF and DREB genes in tomato growth and development, the expression levels of ERF and DREB subfamily members were analyzed according to tomato RNA-Seq data abtained from NCBI SRA library. Seven tomato CBF proteins had the PKKPAGR motif in the N-terminal and the DSAWR motif in the C-terminal of the AP2 domain, but these highly similar proteins to CBF did not have the same motif (Fig. 4a). CBF proteins had N/D9W13V14C15 in 32 , while other proteins had N/S/A9W13V14S15 (Fig. 4a). This analysis suggests that CBF and its highly similar proteins may process different abilities with GCC and/or DRE boxes, which leads them to play different roles in regulating tomato growth, development, and defense responses to abiotic stress.

In different tomato organs, SIERF8-2 was mainly expressed in mature petals and sepals, cotyledons, hypocotyl, and leaf lamina and veins; SIERF8-3 was only expressed in mature petals and sepals, and hardly in other organs. SIERF12-11 and SIERF1-3 were hardly expressed in all organs, except SIERF1-3 in young stamen. SIERF3-6 was mainly expressed in mature sepals, hypocotyl, leaf lamina and veins, and internodes. SIERF3-7 was expressed in mature anthers and petals, young and mature sepals, meristems after transitioning to flowering, cotyledons, hypocotyl, leaf lamina and veins, root apexes and roots without apexes, and internodes, especially in cotyledons, hypocotyl, and leaf lamina. SIERF3-22 was expressed in mature anthers, petals and sepals, meristems after transitioning to flowering, cotyledons, hypocotyl, leaf lamina, and internodes (Fig. 4b; Data S1). These results indicate that 6 CBF genes, except SIERF12-11, may be involved in regulating the development of some floral organs, meristems after transitioning to flowering, cotyledons, hypocotyl, leaves, roots, and internodes. Although other highly similar DREB proteins to CBF do not have PKKPAGR and DSAWR motifs, most of these proteins play roles in some tomato organs. For example, SIERF6-1 was expressed in mature petals and sepals, meristems after transitioning to flowering, cotyledons, hypocotyl, and leaf veins. SIERF812 and SIERF8-11 were highly expressed in mature anthers and young sepals, respectively, but were lowly expressed or undetectable in other organs. SIERF3-20 was highly expressed in some organs, including mature anthers, floral meristems, meristems after transitioning to flowering, vegetative meristems, hypocotyls, leaf veins, young leaves, and internodes; SIERF6-8 was highly expressed in hypocotyls and internodes. These results indicate that CBFs and some DREB genes that are highly similar to CBF regulate the development of the same organs, such as the expression of SIERF8-2, SIERF3-7, SIERF3-22, SIERF6-1, and SIERF3-20 in meristems after transitioning to flowering (Fig. 4b; Data S1).

Among 7 CBF genes, SIERF12-11 and SIERF1-3 did not respond to abiotic stress, including drought, heat, cold, strong light, and red light. SIERF82 and SIERF8-3 positively responded to cold and red light, but not to drought, heat, or strong light. SIERF3-6 was positively induced by heat and red light, negatively regulated by drought, and did not respond to cold or strong light. SIERF3-7 was positively induced by heat, cold, and strong and red lights, but did not change due to drought. SIERF3-22 responded to cold, and strong and red lights, but did not change due to drought or heat (Fig. 4c; Data S2). These results suggest that different CBF genes may play different roles in response to different abiotic stressors. However, some DREB genes that are highly similar to CBF also responded to abiotic stress, including SIERF6-1, SIERF1-13, SIERF12-9, and SIERF6-8, which up-regulated by drought, and SIERF6-1, SIERF8-4, SIERF8-12, and SIERF12-2, which up-regulated by cold. SIERF9-1 and SIERF109 were not expressed or induced by abiotic stress, while SIERF8-10 and SIERF8-11 were lowly expressed under abiotic stress (Fig. 4c; Data S2).

Under biotic stress, among 7 CBF genes, SIERF8-2, SIERF3-6, SIERF3-7, and SIERF3-22 were up-regulated by the tomato spotted wilt virus (TSWV), did not respond to the southern tomato virus (STV), tomato leaf curl Sardinia virus (TYLCSV), and tomato psyllid (Bactericera cockerelli), and were down-regulated by Fusarium oxysporum. SIERF8-2 was down-regulated by F. oxysporum and did not respond to other biotic stressors. SIERF12-11 and SIERF1-3 were not expressed by any biotic stress (Fig. 4C; Data S3). Among the DREB genes that were highly similar to CBF, SIERF1-13, SIERF5-5, SIERF12-2, and SIERF6-8 only responded to TSWV. SIERF6-1 and SIERF8-12 were only down-regulated by $F$. oxysporum and hardly responded to biotic stress. Other DREB genes were hardly regulated by any biotic stressor (Fig. 4c; Data S3).

\section{Expression analysis of repressor genes in tomato}

Among the 140 ERF proteins, 11 ERF and 6 DREB subfamily proteins, which have 1 or 2 typical EAR (LxLxL or DLNxxP) motifs, were found. SIERF10-1, SIERF7-5, SIERF12-1, SIERF7-2, SIERF4-11, SIERF9-1, SIERF2-10, and SIERF4-10 had a DLNxxP motif in the C-terminal, SIERF2-6, SIERF3-16, SIERF8-14, and SIERF4-1 had an LXLXL motif in the C-terminal, and SIERF9-10 and SIERF5-8 had an LxLXL motif in the N-terminal. SIERF7-3, SIERF10-2, and SIERF3-4 had an independent LxLXL motif and DLNXXP motif in the C-terminal. The DLNxxP motif of SIERF7-3 and SIERF10-2 connected with LxLXL sequences and formed a strong repressive motif (Fig. 5a).

To understand the function of the 17 repressor genes, the expression levels of these genes were analyzed in tomato flowers, fruits, meristems, seeds, leaves, and roots. Among these genes, SIERF10-1, SIERF7-5, SIERF12-1, SIERF7-2, SIERF7-3, SIERF10-2, and SIERF2-10 were largely expressed in almost all organs. SIERF2-6, SIERF3-4, SIERF4-10, and SIERF5-8 were expressed in most organs, including flowers, seeds, and leaves. SIERF2-6 and SIERF3-4 were not expressed in the fruits, in contrast to SIERF4-10 and SIERF5-8. SIERF3-16 was only expressed in the floral and vegetative meristems, seeds, and young leaves. SIERF4-11 was only expressed in the seeds. SIERF8-14 and SIERF4-1 were lowly expressed in almost all organs. SIERF9-10 and SIERF9-1 were not expressed in almost all organs (Fig. 5b; Data S1). These results indicated that SIERF10-1, SIERF7-5, SIERF12-1, SIERF7-2, SIERF7-3, SIERF10-2, and SIERF2-10 were involved in regulating the development of almost all organs, while other repressor genes, except SIERF9-10 and SIERF9-1, played roles in regulating the development of some organs. 
Among the 17 repressor genes, at least 13 were expressed in every organ, especially 16 in green large seeds (Fig. S1a; Data S1). Most activator genes were expressed in every organ, including a maximum of 94 genes in mature petals and minimum of 65 in red pulp (Fig. S1a; Data S1). However, the total TPM values of 17 repressor genes had a very high ratio among all ERF genes in every organ and exceeded the activator genes in most organs, including $56.14 \%$ in mature flowers, $57.64 \%$ in floral meristems, $56.58 \%$ in vegetative meristems, and $60.05 \%$ in cotyledons (Fig. S1b; Data S1). These results suggested that the 17 repressor genes play important roles in balancing the regulatory functions of other ERF and DREB subfamily genes and their downstream target genes during tomato growth and development.

Under drought stress, the expression of SIERF3-4 and SIERF4-10 increased, but other repressor genes did not change compared to the control (CK). The expression of SIERF10-1, SIERF2-6, SIERF10-2, SIERF5-8, and SIERF4-1 increased under heat stress, in contrast to SIERF8-14 (Fig. 5c; Data S2). SIERF7-3, SIERF10-2, SIERF8-14, SIERF5-8, and SIERF4-1 responded to cold stress, but other genes were not induced. Only SIERF10-2 was positively regulated by strong light at forenoon and SIERF8-14 was negatively regulated under strong light. SIERF10-1, SIERF2-6, SIERF7-3, SIERF10-2, SIERF2-10, and SIERF4-10 responded to red light stress (Fig. 5c; Data S2). A handful of ERF repressor genes responded to some biotic stressors, including SIERF10-1, SIERF7-5, SIERF7-3, and SIERF10-2, which were up-regulated after induction with TSWV in tomato species SW-7 and Fla.8059. SIERF2-6 was down-regulated by the STV, in contrast to the TYLCSV. SIERF8-14 was down-regulated by the TSWV and $F$. oxysporum. However, most ERF repressor genes, including SIERF7-2, SIERF3-16, SIERF9-10, SIERF4-11, SIERF9-1, SIERF2-10, and SIERF4-10, did not respond to the STV, TYLCSV, tomato psyllid, TSWV, or F. oxysporum (Fig. 5c; Data S3). These results suggest that some repressor genes are involved in regulating tomato tolerance to abiotic and biotic stress.

\section{Expression analysis of ERF genes in the II-A subgroup}

Among the 14 ERF subfamily genes in the II-A subgroup, the 5th, 23th, 24th, 46th, and 48th amino acids of the AP2 domain exhibited unique characteristics. SIERF4-2, SIERF4-5, SIERF4-7, SIERF12-12, SIERF3-17, SIERF6-10, SIERF12-8, SIERF1-16, and SIERF10-3 had V5A23A24L/I46F48, while SIERF1-6, SIERF9-6, SIERF12-10, SIERF3-21, and SIERF6-6 had I5G23V/I24R/K46I48 (Fig. 6a). These differences may affect the ability of ERF proteins to bind with DRE and GCC boxes during the regulation of growth, development, and tolerance to abiotic and biotic stress.

In 30 tomato organs, SIERF1-6, SIERF9-6, SIERF12-10, SIERF3-21, and SIERF6-6 were largely expressed in almost all organs, but SIERF4-7, SIERF12-12, SIERF3-17, SIERF12-8, SIERF1-16, and SIERF10-3 were only expressed in some organs, including SIERF4-7in mature anthers, styles, and seeds, and SIERF12-12 in mature anthers, mature carpels, styles, ovaries, mature petals, mature sepals, and seeds. SIERF4-2, SIERF4-5, and SIERF6-10 exhibited low transcription levels in some organs and were not expressed in most organs (Fig. 6b; Data S1). These results suggest that most of the II-A subgroup genes play roles in regulating tomat growth and development.

All II-A subgroup genes did not respond to drought or strong light stress, but some of these genes were up-regulated by heat, cold, and red light. For example, the expression of SIERF4-2, SIERF1-16, and SIERF6-6 increased under cold and red light stress, and SIERF9-6, SIERF12-10, and SIERF6-6 increased under heat stress (Fig. 6c; Data S2). These results indicate that some of the II-A subgroup genes improve heat, cold, and red light tolerance. However, all II-A subgroup genes did not respond to biotic stress and some genes were even down-regulated, including SIERF116 and SIERF10-3 under F. oxysporum treatment (Fig. 6c; Data S3). These results suggest that the II-A subgroup genes were not involved in enhancing the tolerance to biotic stress.

\section{Expression analysis of DREB genes in the I-B subgroup}

Among the 14 DREB genes in the I-B subgroup, the 12th, 19th, 39th, 43th, 47th, 48th, and 49th amino acids of the AP2 domain exhibited unique characteristics. SIERF3-14, SIERF12-4, SIERF6-4, SIERF6-7, SIERF3-15, and SIERF6-9 had S12H19R39E43L47M48S/C49, while SIERF9-10, SIERF8-5, SIERF8-14, SIERF4-6, SIERF12-13, SIERF4-9, SIERF7-4, and SIERF12-5 had K12L19F/Y/L/M39T/R/K/V43M/K/R47L48R49 (Fig. 7a). SIERF9-10 and SIERF8-14 also show an EAR motif. These characteristics indicate that the ability of the I-B subgroup genes to bind with DRE and/or GCC boxes may be different, and these genes play different roles in regulating tomato growth and development.

Among the 14 DREB genes, SIERF4-6 and SIERF4-9 were highly expressed in all tomato organs, but other genes were specifically expressed in some organs, including SIERF3-14 in young stamens, young sepals, and senescent leaves, SIERF6-4 in young sepals and seeds, and SIERF3-15 in red and dry seeds. SIERF12-5 was not expressed in any tomato organs (Fig. 7b; Data S1). These results suggest that the I-B subgroup genes, except SIERF12-5, are involved in regulating different tomato growth and development processes.

Under abiotic stress, the expression of all I-B subgroup genes did not increase and SIERF8-5 was down-regulated by drought stress. Under heat stress, the expression of SIERF6-4 and SIERF8-14 decreased, SIERF4-9 and SIERF7-4 increased, and other genes did not change. SIERF8-14, SIERF4-9, and SIERF7-4 were up-regulated by cold stress, while other genes did not change. Almost all I-B subgroup genes did not respond to strong or red light stress, but SIERF3-14 and SIERF6-7 were positively regulated and SIERF6-4 was negatively regulated by red light (Fig. 7c; Data S2). All I-B subgroup genes did not positively respond to biotic stress (Fig. 7c; Data S3). These results indicate that a few I-B subgroup genes play roles in abiotic stress responses and all I-B subgroup genes are not involved in biotic stress responses.

Page $8 / 29$ 


\section{Discussion}

\section{Conserved sequence characteristics of the AP2 domain affected the ability of ERF proteins to bind with DRE and GCC boxes}

DRE/CRT and GCC boxes are two cis-acting elements that ERF and DREB subfamily members bind to in higher plants. In previous reports, the 14th and 19th amino acids of the AP2 domain were used to distinguish DREB and ERF proteins, including V14E19, and A14D19, which were respectively named DREB and ERF proteins. Additionally, DRE/CRT and GCC boxes only interact with DREB and ERF proteins, respectively [11]. However, an increasing number of reports have proved that some DREB and ERF proteins can interact with both DRE/CRT and GCC boxes [34, $37,38,44,53,54]$, while a few DREB proteins can only bind with GCC box and a few ERF proteins can only bind with DRE/CRT element [34]. These findings suggest that the 14th and 19th amino acids of the AP2 domain play certain roles in interacting with DRE/CRT and GCC boxes, but some other amino acids also have important functions.

In this study, 140 AP2/ERF proteins with a single AP2 domain in tomato were classified into 6 groups (Fig. 1). Among these proteins, 60 and 80 members were distinguished as DREB- and ERF-type, respectively. Among the DREB-type proteins, there were 30 proteins with V14E19, 27 with V14 and D/N/G/H/L/A/V19, and 3 proteins with I14 and D/V19. E and D have the same characteristics, but others exhibit different characteristics (Table 1). Thus, AP2 domains with either E19 or D19 are not affected by the ability to bind with DRE/CRT or GCC boxes. For example, At5g19790 with V14D19 and At1g75490 with V14E19 can interact with DRE/CRT and GCC boxes [34]. Among the ERF-type proteins, there were 70 proteins with A14D19, 4 with A14Y19, A14N19, T14D19, and E14D19, 4 with S14D19, and 2 with G14N19 (Table 2). In tomato, SIERF3-12 and SIERF5-8 with A14D19 only bind to GCC box [33], but SIERF9-9, SIERF3-21, SIERF6-6, and SIERF9-6 with A14D19 can interact with DRE/CRT and GCC boxes [39, 41-43]. In addition, SIERF5-7 with S14D19 also bound to DRE/CRT and GCC boxes (Fig. 3) [36]. These results suggest that the 14th and 19th amino acids of the AP2 domain cannot be the only standard by which to evaluate the ability of ERF and DREB subfamily members binding with DRE/CRT and GCC boxes.

In this study, we compared the AP2 domain sequences of 68 ERF and DREB proteins from 20 species. The ability of these proteins to bind with DRE/CRT and GCC boxes were demonstrated by EMSA, yeast one-hybrid, and proteome chip assays. We found that 46 proteins with P/H9 in the AP2 domain, except At4g23750, can interact with GCC box, 28 of which can also bind with DRE/CRT box (Fig. 3). However, 5 DERB proteins with S9 in the AP2 domain only interacted with DRE/CRT box. Other site sequences of these 5 proteins did not display some typical differences compared to other DREB proteins that bind to DRE/CRT and GCC boxes (Fig. 3). These results indicate that the 9th amino acid of the AP2 domain plays an important role in protein selection at its binding sites for DRE/CRT and/or GCC boxes. In tomato, 11 DREB proteins had S9, and 70 ERF and 19 DREB had P/H9 at the 9th amino acid of the AP2 domain. These results suggest that DREB proteins with S9 may only interact with DRE/CRT box, and ERF and DREB proteins with P/H9 may bind to GCC box or to both DRE/CRT and GCC boxes. However, the ability of these proteins without S/P/H9 binding with DRE/CRT and GCC boxes is poorly understood. For example, the 9th amino acid of 6 CBF proteins in tomato is $\mathrm{N}$ or $\mathrm{D}$, and some Arabidopsis DERB proteins with N9 can interact with only DRE/CRT or both DRE/CRT and GCC boxes $[34,55,56]$. The abilities of DREB proteins with D9 were not demonstrated by EMSA, yeast one-hybrid, or proteome chip assays.

Functionally, ERF and DREB subfamily proteins work as activators or repressors in plant growth, development, and defense responses. Proteins, including EAR motif, can repress the expression of downstream target genes by recruiting a histone deacetylase complex to affect chromatin structures [57-59]. However, although some reports have verified that EDLL motif is an activating domain [60-62], the activating domain of ERF and DREB subfamily proteins is complex and remains elusive. In tomato, EDLL motif is only displayed in some the II-B group members (Fig. S2), but this motif was included in motif 6. Some members of the I-A group including CBF and a few members of the II-B group also had motif 6 (Fig. 2). These findings suggest that motif 6 instead of the EDLL motif may be a more reliable transactivation domain. The MEME analysis results suggest that motifs $1,2,3$, and 4 are located in the AP2 domain, while others are distributed outside the AP2 domain. Thus, motifs relatively distant from the AP2 domain, including motifs 7-9, 11, 12, 14, 17-19, and 22-24 may also act as a part of the transactivation domain. Motifs near the AP2 domain, including motifs 5, 10, 13, 15, 20, 24, and 25 may help the AP2 domain bind to DRE/CRT and GCC boxes (Fig. 2). For example, the PKKPAGR signature sequence of Arabidopsis CBF1 is located near the left of the AP2 domain and mutations within this motif reduce the ability of CBF1 to bind to DRE/CRT element and decrease the expression levels of the COR gene [63]. In this study, motif 10 included the PKKPAGR signature sequence and was located near the left of the AP2 domain in 7 tomato CBF proteins (Fig. 4 a). These results indicate that these motifs near the AP2 domain may play important roles in helping the AP2 domain to bind to DRE/CRT and GCC boxes, but the functions of motifs far away from the AP2 domain remain unclear during the regulation of transcription of downstream genes.

\section{ERF repressors balance the regulatory functions of other ERF activating genes during tomato growth, development, and defense responses}

AP2/ERF TFs play important roles in regulating plant growth, development, and defense responses. For example, AtERF115 can repress adventitious rooting in Arabidopsis through the JA and CTK signaling pathways [64], but PUCHI (At5g18560) can positively regulate floral meristems, organ initiation, and lateral root development in Arabidopsis [12, 13]. Rice OsERF101 regulates leaf senescence and responses to drought stress in reproductive tissues $[65,66]$. These findings suggest that some ERF proteins often regulate several plant life processes. However, an ERF protein can only act as an activator or repressor. In this study, we found that there were 11 ERF and 6 DREB proteins including 
the EAR repression domain, in tomato. Among these proteins, SIERF7-3 and SIERF10-2 had 2 LxLxL and 1 DLNxxP, and SIERF3-4 had 1 LxLxL and 1 DLNxxP at the C-terminal. These results suggest that SIERF7-3, SIERF10-2, and SIERF3-4 may recruit more histone deacetylase complexes to repress the expression of their downstream target genes. The expression levels of SIERF10-2 (LeERF3b) markedly increased in low ET tomato fruit containing an ACC oxidase sense-suppression transgene and in the ET insensitive mutant never ripe (Nr), in contrast to SIERF5-10 (Pti4) without the EAR motif [67]. SIERF5-10 regulated fruit ripening, seed germination, and responses to biotic and abiotic stress [68-71]. In this study, SIERF7-3, SIERF10-2, and SIERF3-4 were expressed in several organs, especially SIERF7-3 and SIERF10-2, which were highly expressed in tomato all flowers, fruits, meristems, seeds, leaves, and roots (Fig. $5 \mathrm{~b}$ ). The 3 genes also responded to some biotic and abiotic stressors (Fig. 5c). These results indicate that SIERF7-3, SIERF10-2, and SIERF3-4 as repressors are involved in several metabolic pathways that affect tomato growth, development, and defense responses. Other genes, including SIERF10-1, SIERF7-5, SIERF12-1, SIERF7-2, SIERF2-6, SIERF2-10, SIERF4-10, SIERF5-8, and SIERF4-1, were also highly expressed in several tomato organs. Overexpression of SIERF10-1 (SIERF36) caused early flowering and plant senescence, and affected stomatal density, photosynthesis, and plant growth [72]. These findings suggest that they may play the same or similar roles, like SIERF7-3, SIERF10-2, and SIERF3-4. However, SIERF9-1 was not expressed in any tomato organ or under biotic and abiotic stress. Moreover, its EAR motif was located in the AP2 domain terminal. Thus, SIERF9-1 may be an invalid gene. SIERF3-16, SIERF9-10, SIERF8-14, and SIERF4-11 were expressed some tomato organs and under biotic and abiotic stress (Fig. 5b and c). SIERF3-16 (ENO) was involved in the CLAVATA-WUSCHEL signaling pathway that regulates floral meristem development [73]. These results indicate that these genes play repression roles in some organs and under certain environmental conditions.

Although there are 60 DREB and 80 ERF subfamily members in tomato, only 11 ERF and 5 DREB genes, except SIERF9-1, as repressors were expressed in all or some tomato organs or under biotic and abiotic stress. In this study, we analyzed the expressed gene numbers of all repressors and activators in every tomato organ and found that at least 13 repressor genes were expressed in several floral organs, red pulp, cotyledons, and senescent leaves, and, at most, 16 repressor genes were expressed in green large seeds (Fig. S1a). However, most activator genes were expressed in every organ, including the maximum of 94 genes in mature petals and the minimum of 65 in red pulp (Fig. S1a). The TPM value ratios of all expressed repressors and activators were compared. Results indicated that the ratio of repressors exceeded that of activators in 16 tomato organs, especially in cotyledons (Fig. S1b), suggesting that the 16 repressor genes control the activation function of other ERF and DREB genes by competing with the binding sites of their target genes, and finally balancing the expression of their target genes to ensure normal growth and development.

Among the activators, the expression of most members showed tissue and spatiotemporal specificity, including SIERF8-3, SIERF3-6, SIERF3-7, SIERF3-22, SIERF6-1, SIERF12-2 (LEDREB2), and SIERF8-12 in the I-A subgroup (Fig. 4b and c), SIERF4-7, SIERF12-12, and SIERF10-3 in the II-A subgroup (Fig. 6b and c), and SIERF3-14, SIERF6-4, SIERF3-15, and SIERF8-14 in the I-B subgroup (Fig. 7b and c). Among these genes, only SIERF12-2 responded to drought, cold, and salt [74], and the functions of other genes remain unclear. Some activator genes were expressed in almost all tomato organs and responded to some biotic and abiotic stressors, including SIERF1-6, SIERF9-6, SIERF12-10, SIERF3-21, and SIERF6-6 in the II-A subgroup (Fig. 6b and c), and SIERF4-6 and SIERF4-9 in the I-B subgroup (Fig. 7b and c). Their expression patterns were highly similar with most repressor genes. Although SIERF1-6 regulated the biosynthesis of carotenoids and ET during fruit ripening [75], SIERF96 regulated ET biosynthesis, seed germination, and defense responses [43, 76-78], and SIERF4-9 was involved in plant growth, root architecture, and responses to abiotic stress [79-81]. However, their functions in other tomato organs remain unclear. Moreover, these genes may conversely limit repressor activities, and ensure the normal growth and development of tomato plants is not overly inhibited.

\section{Conclusions}

This work highlights that much remains to be understood about the relationship between repressors and activators in tomato ERF and DREB subfamily members. By performing Pfam model (pf00847) search and sequences comparing in 3 tomato genome sequencing databases (versions 2.0, 3.2, and 4.0), 140 AP2/ERF genes were identified. These genes included 60 DREB and 80 ERF subfamily members and were classified into six subgroups. The expression profiles of DREB and ERF genes in 30 tomato organs as well as under biotic and abiotic stresses were investigated and compared, which could considered as the candidates for further study of their function in plant growth, development, and defense response.

\section{Declarations}

\section{Acknowledgements}

This work was supported by the National Natural Science Foundation of China (Grant No. 31772295, U1708232, 31991184), China Agriculture Research System (Grant No. CARS-25). We thank LetPub (www.letpub.com) for providing its linguistic assistance during the preparation of this manuscript.

Availability of data and material

Page 10/29 
All of the datasets supporting the results of this article are included within the article and its Additional files.

\section{Authors' contributions}

LZ, MQ, and YL conceived and designed this study. LC, SP, QZ, SQ, and YL carried out genome-wide identification and sequence analysis of the AP2/ERF genes. TX, LZ, and YL carried out expression analysis of the AP2/ERF genes. LZ, MQ, and YL drafted and revised the manuscript. All authors read and approved the final manuscript.

\section{Competing interests}

The authors declare that they have no competing interests.

\section{Consent for publication}

Not applicable.

\section{Ethics approval and consent to participate}

Not applicable.

\section{Author details}

${ }^{1}$ College of Agriculture, Shihezi University, Shihezi, China, ${ }^{2}$ College of Bioscience and Biotechnology, Shenyang Agricultural University, Shenyang, China, ${ }^{3}$ College of Horticulture, Shenyang Agricultural University, Shenyang, China, ${ }^{4}$ Key Laboratory of Agricultural Biotechnology of Liaoning Province, Shenyang Agricultural University, Shenyang, China

\section{References}

1. Pieterse CMJ, Leon-Reyes A, Van der Ent S, Van Wees SCM. Networking by small-molecule hormones in plant immunity. Nat Chem Biol. 2009;5:308-16

2. Davies, Peter J. Plant hormones and their role in plant growth and development. Q Rev Biol. 1988;63:225.

3. Yamasaki K, Kigawa T, Seki M, Shinozaki K, Yokoyama S. DNA-binding domains of plant-specific transcription factors: structure, function, and evolution. Trends Plant Sci. 2013;18:267-76.

4. Dietz KJ, Vogel MO, Viehhauser A. AP2/EREBP transcription factors are part of gene regulatory networks and integrate metabolic, hormonal and environmental signals in stress acclimation and retrograde signalling. Protoplasma. 2010;245:3-14.

5. Song X, Li Y, Hou X. Genome-wide analysis of the AP2/ERF transcription factor superfamily in Chinese cabbage(Brassica rapa ssp. pekinensis). BMC Genom. 2013;14:573.

6. Ji AJ, Luo HM, Xu ZC, Zhang X, Zhu YJ, Liao BS, Yao H, Song JY, Chen SL. Genome-wide identification of the AP2/ERF gene family involved in active constituent biosynthesis in Salvia miltiorrhiza. Plant Genome. 2016;9:1-11.

7. Akhter Most S, Mohammed N, Kouji S, Takumi S, Hiroaki K, Takahide S, Il-Ryong C, Toshihiro O, Shoshi K. Gene structures, classification and expression models of the AP2/EREBP transcription factor family in rice. Plant Cell Physiology. 2011;52:344-60.

8. Ma Y, Zhang F, Bade R, Daxibater A, Men Z, Hasi A. Genome-wide identification and phylogenetic analysis of the ERF gene family in melon. J Plant Growth Regul. 2015;34:66-77.

9. Chen Y, Wu P, Zhao Q, Tang Y, Chen Y, Li M, Jiang H, Wu G. Overexpression of a phosphate starvation response AP2/ERF gene from physic nut in Arabidopsis alters root morphological traits and phosphate starvation-induced anthocyanin accumulation. Front Plant Sci. 2018;9:1186.

10. Nakano T, Suzuki K, Fujimura T, Shinshi H. Genome-wide analysis of the ERF gene family in Arabidopsis and rice. Plant Physiol. 2006;140:411.

11. Sakuma Y, Liu Q, Dubouzet JG, Abe H, Shinozaki K, Yamaguchi-Shinozaki K. DNA-binding specificity of the ERF/AP2 domain of Arabidopsis DREBs, transcription factors involved in dehydration- and cold-inducible gene expression. Biochemical Biophysical Research Communications. 2002;290:998-1009.

12. Hirota A, Kato T, Fukaki H, Aida M, Tasaka M. The auxin-regulated AP2/EREBP gene PUCHI is required for morphogenesis in the early lateral root primordium of Arabidopsis. Plant Cell. 2007;19:2156-68.

13. Chandler JW, Werr W. DORNROSCHEN, DORNROSCHEN-LIKE, and PUCHI redundantly control floral meristem identity and organ initiation in Arabidopsis. J Exp Bot. 2017;68:3457-72. 
14. Sakuma Y, Maruyama K, Osakabe Y, Qin F, Seki M, Shinozaki K, Yamaguchi-Shinozaki K. Functional analysis of an Arabidopsis transcription factor, DREB2A, involved in drought-responsive gene expression. Plant Cell. 2006;18:1292-309.

15. Sakuma Y, Maruyama K, Qin F, Osakabe Y, Yamaguchi-Shinozaki K. Dual function of an Arabidopsis transcription factor DREB2A in waterstress-responsive and heat-stress-responsive gene expression. Proc Natl Acad Sci USA. 2007;103:18822-7.

16. Vainonen JP, Jaspers P, Wrzaczek M, Lamminmaki A, Reddy RA, Vaahtera L, Brosche M, Kangasjarvi J. RCD1-DREB2A interaction in leaf senescence and stress responses in Arabidopsis thaliana. Biochem J. 2012;442:573.

17. Berrocal-Lobo M, Molina A, Solano R. Constitutive expression of ETHYLENE-RESPONSE-FACTOR1 in Arabidopsis confers resistance to several necrotrophic fungi. Plant J. 2002;29:23-32.

18. McGrath kC, Dombrecht B, Manners JM, Schenk PM, Edgar Cl, Maclean DJ, Scheible WR, Udvardi MK, Kazan K. Repressor- and activatortype ethylene response factors functioning in jasmonate signaling and disease resistance identified via a genome-wide screen of Arabidopsis transcription factor gene expression. Plant Physiol. 2005;139:949-59.

19. Fujimoto SY, Ohta M, Usui A, Shinshi H, Ohme-Takagi M. Arabidopsis ethylene-responsive element binding factors act as transcriptional activators or repressors of GCC Box-mediated gene expression. Plant Cell. 2000;12:393-404.

20. Liu Q, Kasuga M, Sakuma Y, Abe H, Miura S, Yamaguchi-Shinozaki K, Shinozaki K. (1998). Two transcription factors, DREB1 and DREB2, with an EREBP/AP2 DNA binding domain separate two cellular signal transduction pathways in drought- and low-temperature-responsive gene expression, respectively, in Arabidopsis. Plant Cell 10, 1391-1406.

21. Cheng MC, Hsieh EJ, Chen JH, Chen HY, Lin TP. Arabidopsis RGLG2, functioning as a RING E3 ligase, interacts with AtERF53 and negatively regulates the plant drought stress response. Plant Physiol. 2012;158:363-75.

22. Song CP, Agarwal M, Ohta M, Guo Y, Halfter U, Wang PC, Zhu JK. Role of an Arabidopsis AP2/EREBP-type transcriptional repressor in abscisic acid and drought stress responses. Plant Cell. 2005;17:2384-96.

23. Whelan S, Goldman N. A general empirical model of protein evolution derived from multiple protein families using a maximum-likelihood approach. Mol Biol Evol. 2001;18:691-9.

24. Kumar S, Stecher G, Tamura K. MEGA7: molecular evolutionary genetics analysis version 7.0 for bigger datasets. Mol Biol Evol. 2016;33:1870-4.

25. Waterhouse AM, Procter JB, Martin DM, Clamp M, Barton GJ. Jalview Version 2-a multiple sequence alignment editor and analysis workbench. Bioinformatics. 2009;25:1189-91.

26. Notredame C, Higgins DG, Heringa J. (2000). T-coffee: A novel method for multiple sequence alignments. Journal of Molecular Biology 302.

27. Penin AA, Klepikova AV, Kasianov AS, Gerasimov ES, Logacheva MD. (2019). Comparative analysis of developmental transcriptome maps of Arabidopsis thaliana and Solanum lycopersicum. Genes (Basel) 10.

28. Fukushima A, Hikosaka S, Kobayashi M, Nishizawa T, Saito K, Goto E, Kusano M. A systems analysis with "simplified source-sink model" reveals metabolic reprogramming in a pair of source-to-sink organs during early fruit development in tomato by LED light treatments. Front Plant Sci. 2018;9:1439.

29. Chiumenti M, Catacchio CR, Miozzi L, Pirovano W, Ventura M, and Pantaleo V. A short indel-lacking-resistance gene triggers silencing of the photosynthetic machinery components through TYLCSV-associated endogenous siRNAs in tomato. Front Plant Sci. 2018;9:1470.

30. Tang XT, Longnecker M, Tamborindeguy C. Acquisition and transmission of two 'Candidatus Liberibacter solanacearum' haplotypes by the tomato psyllid Bactericera cockerelli. Sci Rep. 2020;10:14000.

31. Fukuhara T, Tabara M, Koiwa H, Takahashi H. Effect of asymptomatic infection with southern tomato virus on tomato plants. Arch Virol. 2020;165:11-20.

32. Patro R, Duggal G, Love MI, Irizarry RA, Kingsford C. Salmon provides fast and bias-aware quantification of transcript expression. Nat Methods. 2017;14:417-9.

33. Tournier B, Sanchezballesta MT, Jones B, Pesquet E, Regad F, Latché A, Pech JC, Bouzayen M. New members of the tomato ERF family show specific expression pattern and diverse DNA-binding capacity to the GCC box element. Febs Letters. 2003;550:149-54.

34. Gong W, He K, Covington M, Dinesh-Kumar SP, Snyder M, Harmer SL, Zhu YX, Deng XW. The Development of protein microarrays and their applications in DNA-protein and protein-protein interaction analyses of Arabidopsis transcription factors. Mol Plant. 2008;1:27-41.

35. Hao DY, Yamasaki K, Sarai A, Ohme-Takagi M. Determinants in the sequence specific binding of two plant transcription factors, CBF1 and NtERF2, to the DRE and GCC motifs. Biochemistry. 2002;41:4202-8.

36. Huang Z, Zhang Z, Zhang X, Zhang H, Huang D, Huang R. Tomato TERF1 modulates ethylene response and enhances osmotic stress tolerance by activating expression of downstream genes. Febs Letters. 2004;573:110-6.

37. Zhang Y, Ji A, Xu Z, Luo H, Song J. (2019). The AP2/ERF transcription factor SmERF128 positively regulates diterpenoid biosynthesis in Salvia miltiorrhiza. Plant Molecular Biology.

Page $12 / 29$ 
38. Wang L, Qin L, Liu W, Zhang D, Wang Y. A novel ethylene-responsive factor from Tamarix hispida, ThERF1, is a GCC-box- and DRE-motif binding protein that negatively modulates abiotic stress tolerance in Arabidopsis. Physiology Plant. 2014;152:84-97.

39. Klay I, Gouia S, Liu M, Mila I, Khoudi H, Bernadac A, Bouzayen M, Pirrello J. Ethylene response factors (ERF) are differentially regulated by different abiotic stress types in tomato plants. Plant Sci. 2018;274:137-54.

40. Solano R, Stepanova A, Chao Q, Ecker JR. Nuclear events in ethylene signaling: a transcriptional cascade mediated by ETHYLENEINSENSITIVE3 and ETHYLENE-RESPONSE-FACTOR1. Genes Development. 1998;12:3703-14.

41. Wu L, Zhang Z, Zhang H, Wang XC, Huang R. Transcriptional modulation of ethylene response factor protein JERF3 in the oxidative stress response enhances tolerance of tobacco seedlings to salt, drought, and freezing. Plant Physiol. 2008;148:1953-63.

42. Zhang H, Huang Z, Xie B, Chen Q, Tian X, Zhang X, Zhang H, Lu X, Huang D, Huang R. The ethylene-, jasmonate-, abscisic acid- and NaClresponsive tomato transcription factor JERF1 modulates expression of GCC box-containing genes and salt tolerance in tobacco. Planta. 2004;220:262-70.

43. Zhang Z, Zhang H, Quan R, Wang XC, Huang R. Transcriptional regulation of the ethylene response factor LeERF2 in the expression of ethylene biosynthesis genes controls ethylene production in tomato and tobacco. Plant Physiol. 2009b;150:365-77.

44. Lee JH, Kim DM, Lee JH, Kim J, Bang JW, Kim WT, Pai HS. Functional characterization of NtCEF1, an AP2/EREBP-type transcriptional activator highly expressed in tobacco callus. Planta. 2005;222:211-24.

45. Xu ZS, Xia LQ, Chen M, Cheng XG, Zhang RY, Li LC, Zhao YX, Lu Y, Ni ZY, Liu L, Qiu ZG, Ma YZ. Isolation and molecular characterization of the Triticum aestivum L. ethylene-responsive factor 1 (TaERF1) that increases multiple stress tolerance. Plant Mol Biol. 2007;65:719-32.

46. Lee SY, Hwang EY, Seok HY, Tarte VN, Jeong MS, Jang SB, Moon YH. Arabidopsis AtERF71/HRE2 functions as transcriptional activator via cis-acting GCC box or DRE/CRT element and is involved in root development through regulation of root cell expansion. Plant Cell Rep. 2015;34:223-31.

47. Park JM, Park CJ, Lee SB, Ham BK, Shin R, Paek KH. Overexpression of the tobacco Tsi1 gene encoding an EREBP/AP2-type transcription factor enhances resistance against pathogen attack and osmotic stress in tobacco. Plant Cell. 2001;13:1035-46.

48. Büttner M., and Singh KB. Arabidopsis thaliana ethylene-responsive element binding protein (AtEBP), an ethylene-inducible, GCC box DNAbinding protein interacts with an ocs element binding protein. Proc Natl Acad Sci USA. 1997;94:5961-6.

49. Licausi F, van Dongen JT, Giuntoli B, Novi G, Santaniello A, Geigenberger P, Perata P. (2010). HRE1 and HRE2, two hypoxia-inducible ethylene response factors, affect anaerobic responses in Arabidopsis thaliana. Plant Journal 62, 302-315.

50. Zhang G, Chen M, Li L, Xu Z, Chen X, Guo J, Ma Y. Overexpression of the soybean GmERF3 gene, an AP2/ERF type transcription factor for increased tolerances to salt, drought, and diseases in transgenic tobacco. J Exp Bot. 2009a;60:3781-96.

51. Jae-Hoon L, Jong-Pil H, Sang-Keun O, Sanghyeob L, Doil C, Woo Taek K. The ethylene-responsive factor like protein 1 (CaERFLP1) of hot pepper (Capsicum annuum L.) interacts in vitro with both GCC and DRE/CRT sequences with different binding affinities: possible biological roles of CaERFLP1 in response to pathogen infection and high salinity conditions in transgenic tobacco plants. Plant Mol Biol. 2004;55:61-81.

52. Lin RC, Park HJ, Wang HY. Role of Arabidopsis RAP2.4 in regulating light- and ethylene-mediated developmental processes and drought stress tolerance. Mol Plant. 2008;1:42-57.

53. Tang M, Sun J, Liu Y, Chen F, Shen S. Isolation and functional characterization of the JcERF gene, a putative AP2/EREBP domaincontaining transcription factor, in the woody oil plant Jatropha curcas. Plant Mol Biol. 2007;63:419.

54. Liu Y, Zhao TJ, Liu JM, Liu WQ, Liu Q, Yan YB, Zhou HM. The conserved Ala37 in the ERF/AP2 domain is essential for binding with the DRE element and the GCC box. FEBS Lett. 2006;580:1303-8.

55. Wei G, Pan Y, Lei J, Zhu YX. Molecular cloning, phylogenetic analysis, expressional profiling and in vitro studies of TINY2 from Arabidopsis thaliana. Journal of Biochemistry Molecular Biology. 2005;38:440-6.

56. Sun S, Yu JP, Chen F, Zhao TJ, Fang XH, Li YQ, Sui SF. TINY, a dehydration-responsive element (DRE)-binding protein-like transcription factor connecting the DRE- and ethylene-responsive element-mediated signaling pathways in Arabidopsis. Journal of Biology Chemistry. 2008;283:6261-71.

57. Yang J, Liu Y, Yan H, Tian T, You Q, Zhang L, Xu W, Su Z. PlantEAR: functional analysis platform for plant EAR motif-containing proteins. Front Genet. 2018;9:590.

58. Hill K, Wang H, Perry SE. A transcriptional repression motif in the MADS factor AGL 15 is involved in recruitment of histone deacetylase complex components. Plant J. 2008;53:172-85.

59. Causier B, Ashworth M, Guo W, Davies B. The TOPLESS interactome: a framework for gene repression in Arabidopsis. Plant Physiol. 2012;158:423-38.

60. Phukan UJ, Jeena GS, Tripathi V, Shukla RK. Regulation of Apetala2/ethylene response factors in plants. Front Plant Sci. $2017 ; 8: 150$. 
61. Ou B, Yin KQ, Liu SN, Yang Y, Gu T, Wing Hui JM, Zhang L, Miao J, Kondou Y, Matsui M, Gu HY, Qu LJ. A high-throughput screening system for Arabidopsis transcription factors and its application to Med25-dependent transcriptional regulation. Mol Plant. 2011;4:546-55.

62. Cevik V, Kidd BN, Zhang P, Hill C, Kiddle S, Denby KJ, Holub EB, Cahill DM, Manners JM, Schenk PM, Beynon J, Kazan K. MEDIATOR25 acts as an integrative hub for the regulation of jasmonate-responsive gene expression in Arabidopsis. Plant Physiol. 2012;160:541-55.

63. Canella D, Gilmour SJ, Kuhn LA, Thomashow MF. DNA binding by the Arabidopsis CBF1 transcription factor requires the PKKP/RAGRxKFxETRHP signature sequence. Biochem Biophys Acta. 2010;1799:454-62.

64. Lakehal A, Dob A, Rahneshan Z, Novak O, Escamez S, Alallaq S, Strnad M, Tuominen H, Bellini C. (2020). ETHYLENE RESPONSE FACTOR 115 integrates jasmonate and cytokinin signaling machineries to repress adventitious rooting in Arabidopsis. New Phytol.

65. Jin Y, Pan W, Zheng X, Cheng X, Liu M, Ma H, Ge X. OsERF101, an ERF family transcription factor, regulates drought stress response in reproductive tissues. Plant Mol Biol. 2018;98:51-65.

66. Lim C, Kang K, Shim Y, Sakuraba Y, An G, Paek NC. Rice ETHYLENE RESPONSE FACTOR 101 promotes leaf senescence through jasmonic acid-mediated regulation of OsNAP and OsMYC2. Front Plant Sci. 2020;11:1096.

67. Chen G, Hu Z, Grierson D. Differential regulation of tomato ethylene responsive factor LeERF3b, a putative repressor, and the activator Pti4 in ripening mutants and in response to environmental stresses. J Plant Physiol. 2008;165:662-70.

68. Gu YQ, Wildermuth MC, Chakravarthy S, Loh YT, Yang C, He X, Han Y, Martin GB. (2002). Tomato transcription factors Pti4, Pti5, and Pti6 activate defense responses when expressed in Arabidopsis. Plant Cell 14, 817-831.

69. Ouyang Z, Liu S, Huang L, Hong Y, Li X, Huang L, Zhang Y, Zhang H, Li D, Song F. (2016). Tomato SIERF.A1, SIERF.B4, SIERF.C3 and SIERF.A3, members of B3 group of ERF family, are required for resistance to Botrytis cinerea. Frontiers in Plant Science 7.

70. Sun YF, Liang B, Wang J, Kai WB, Chen P, Jiang L, Du YW, Leng P. (2018). SIPti4 affects regulation of fruit ripening, seed germination and stress responses by modulating ABA signaling in tomato. Plant and Cell Physiology 59, 1956.

71. Thara VK, Tang X, Gu YQ, Martin GB, Zhou JM. Pseudomonas syringae pv tomato induces the expression of tomato EREBP-like genes Pti4 and Pti5 independent of ethylene, salicylate and jasmonate. Plant J. 1999;20:475-83.

72. Upadhyay RK, Gupta A, Ranjan S, Singh R, Pathre UV, Nath P, Sane AP. The EAR motif controls the early flowering and senescence phenotype mediated by over-expression of SIERF36 and is partly responsible for changes in stomatal density and photosynthesis. Plos One. 2014;9:e101995.

73. Yuste-Lisbona FJ, Fernandez-Lozano A, Pineda B, Bretones S, Ortiz-Atienza A, Garcia-Sogo B, Muller NA, Angosto T, Capel J, JimenezGomez MV J.M., and Lozano R. ENO regulates tomato fruit size through the floral meristem development network. Proc Natl Acad Sci USA. 2020;117:8187-95.

74. Guo J, Wang MH. Expression profiling of the DREB2 type gene from tomato (Solanum lycopersicum L.) under various abiotic stresses. Hortic Environ Biotechnol. 2011;52:105-11.

75. Lee JM, Joung JG, Mcquinn R, Chung MY, Fei Z, Tieman D, Klee H, Giovannoni J. Combined transcriptome, genetic diversity and metabolite profiling in tomato fruit reveals that the ethylene response factor SIERF6 plays an important role in ripening and carotenoid accumulation. Plant J. 2012;70:191-204.

76. Pirrello J, Jaimesmiranda F, Sanchezballesta MT, Tournier B, Khalilahmad Q, Regad F, Latché A, Pech JC, Bouzayen M. SI-ERF2, a tomato ethylene response factor involved in ethylene response and seed germination. Plant Cell Physiology. 2006;47:1195.

77. Yu WQ, Zhao RR, Sheng JP, Shen L. (2018). SIERF2 is associated with MeJA-mediated defense response against Botrytis cinerea in tomato fruit. Journal of Agricultural and Food Chemistry 66.

78. Zhang ZJ, Huang RF. Enhanced tolerance to freezing in tobacco and tomato overexpressing transcription factor TERF2/LeERF2 is modulated by ethylene biosynthesis. Plant Mol Biol. 2010;73:241-9.

79. Islam MS, Wang MH. Expression of dehydration responsive element-binding protein-3 (DREB3) under different abiotic stresses in tomato. BMB Rep. 2009;42:611-6.

80. Upadhyay RK, Gupta A, Soni D, Garg R, Pathre UV, Nath P, Sane AP. Ectopic expression of a tomato DREB gene affects several ABA processes and influences plant growth and root architecture in an age-dependent manner. J Plant Physiol. 2017;214:97-107.

81. Wang GD, Xu XP, Wang H, Liu Q, Yang XT, Liao LX, Cai GH. A tomato transcription factor, SIDREB3 enhances the tolerance to chilling in transgenic tomato. Plant Physiol Biochem. 2019;142:254-62.

\section{Figures}




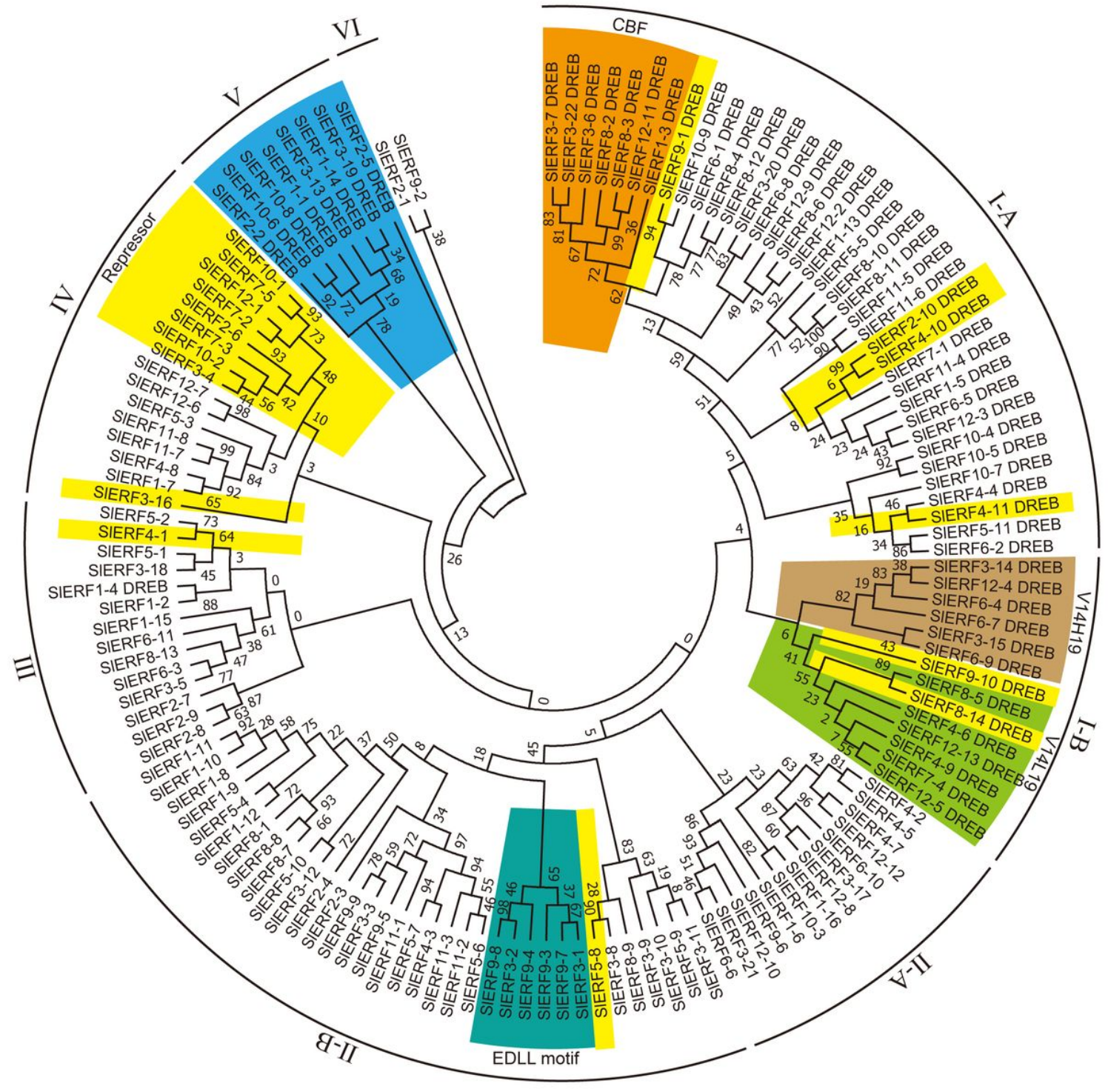

Figure 1

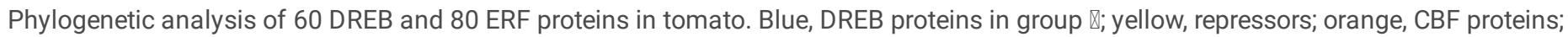
emerald green, activators with EDLL motif; yellow green and latin yellow, respectively indicate DREB proteins with V14L19 and V14H19. Maximum likelihood method was used to structure phylogenetic tree based on the Whelan and Goldman model of MEGA v7.0 [23], parameters: JTT + G model, partial deletion with $80 \%$ site coverage cutoff, and 1000 bootstrap replications [24]. 


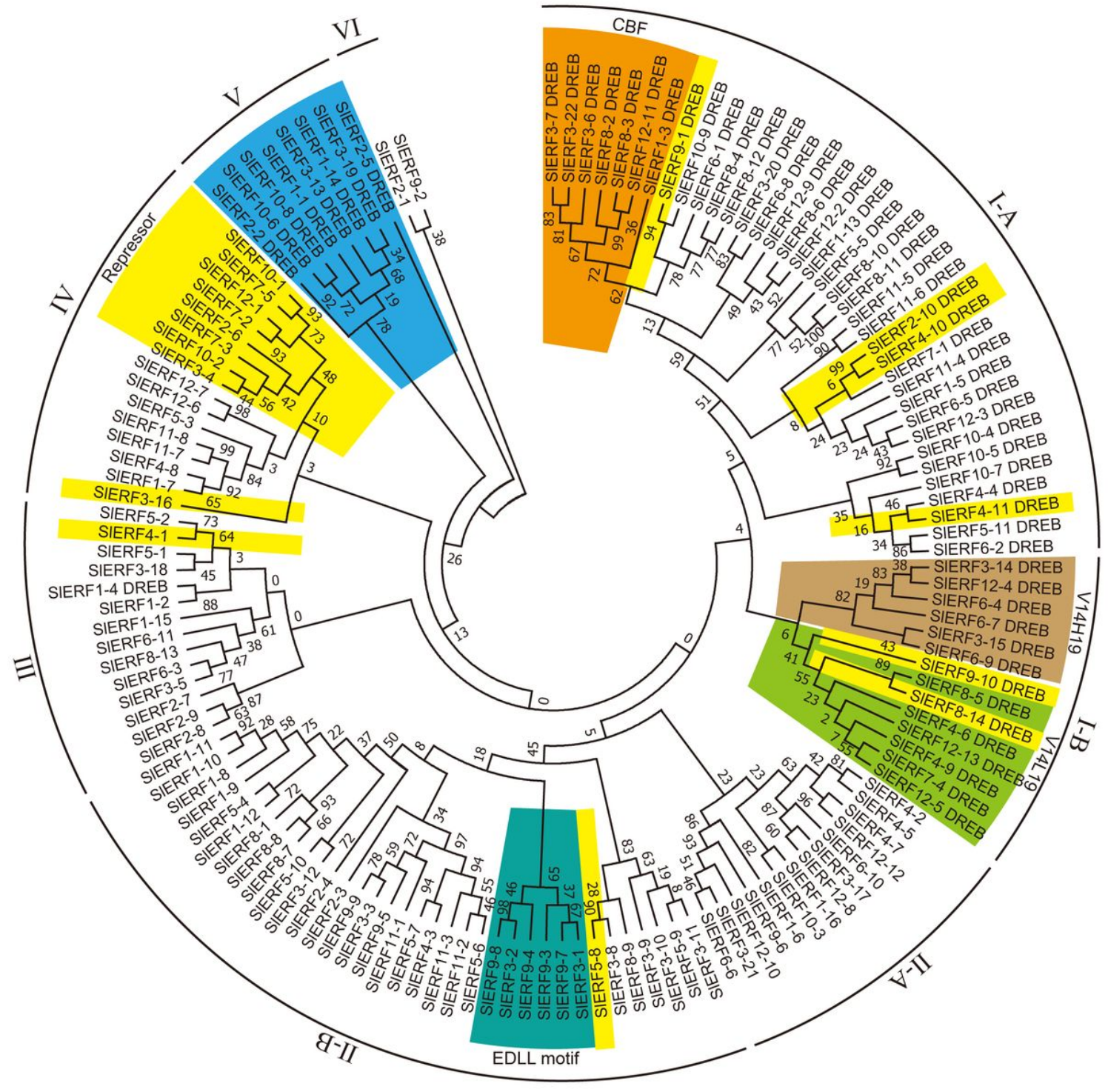

Figure 1

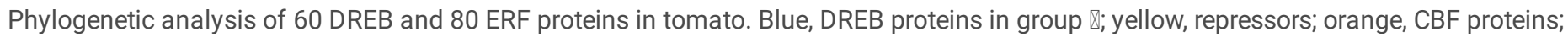
emerald green, activators with EDLL motif; yellow green and latin yellow, respectively indicate DREB proteins with V14L19 and V14H19. Maximum likelihood method was used to structure phylogenetic tree based on the Whelan and Goldman model of MEGA v7.0 [23], parameters: JTT + G model, partial deletion with $80 \%$ site coverage cutoff, and 1000 bootstrap replications [24]. 


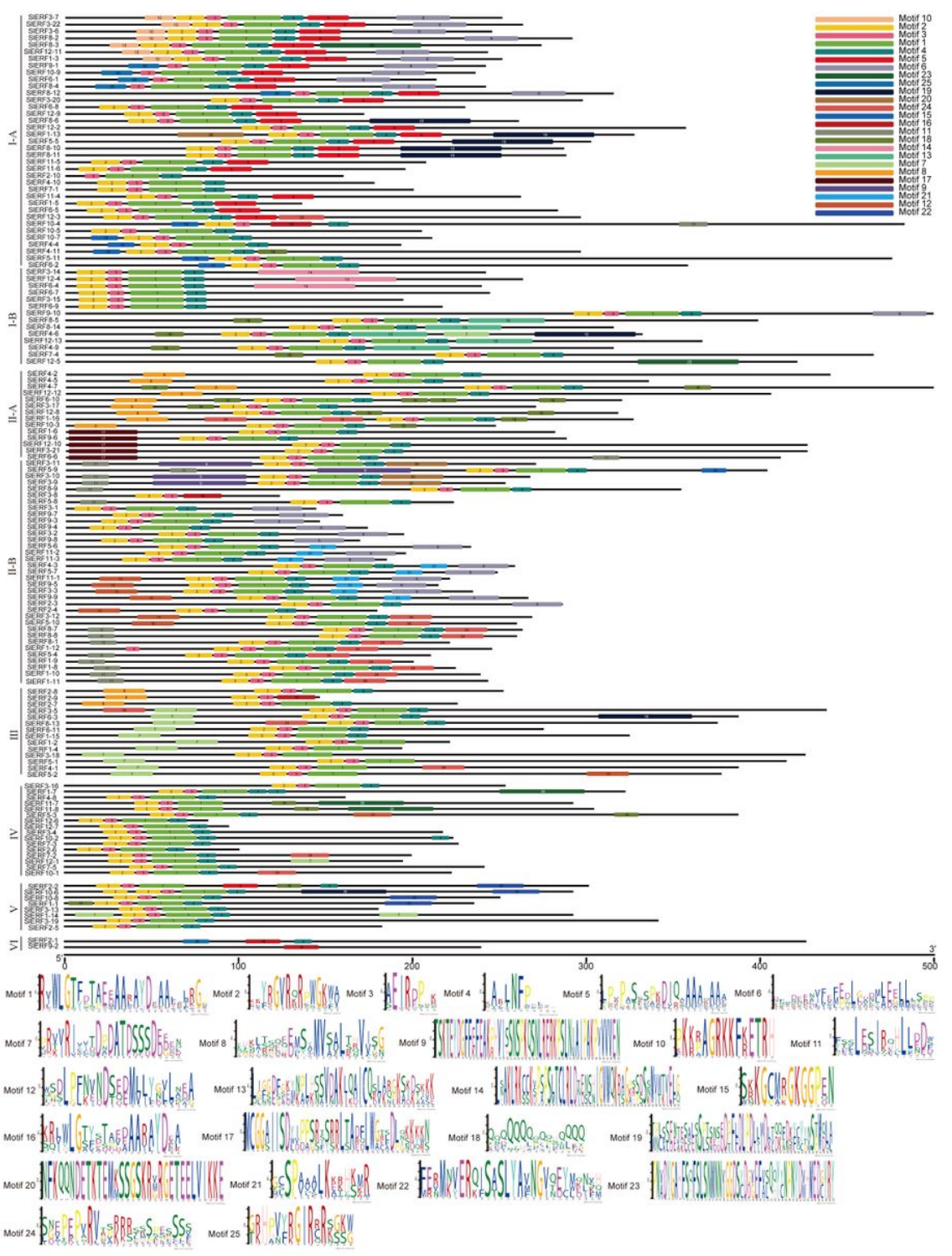

Figure 2

25 motif predictive analysis of 60 DREB and 80 ERF proteins in tomato using a Multiple Em for Motif Elicitation (MEME). 


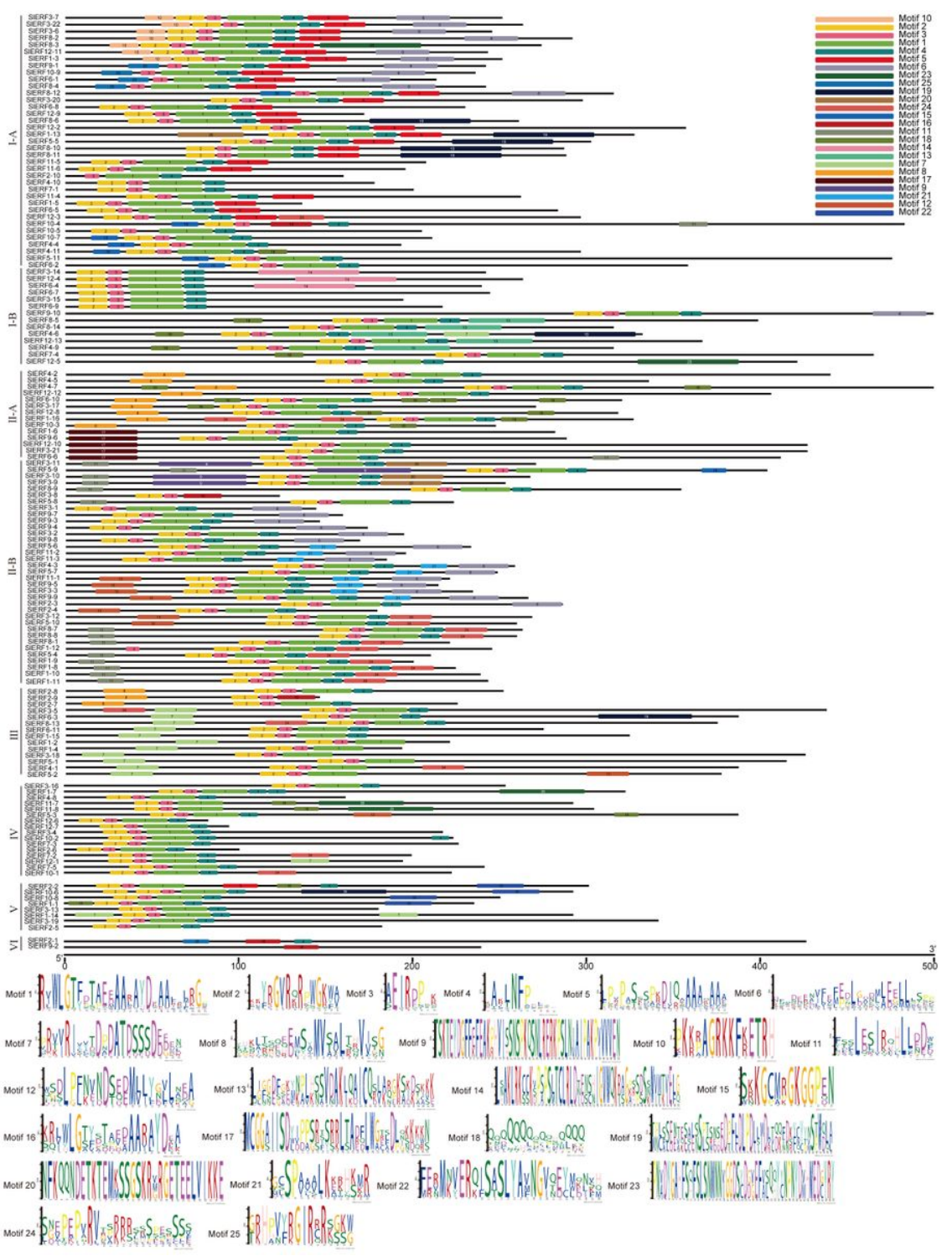

Figure 2

25 motif predictive analysis of 60 DREB and 80 ERF proteins in tomato using a Multiple Em for Motif Elicitation (MEME). 


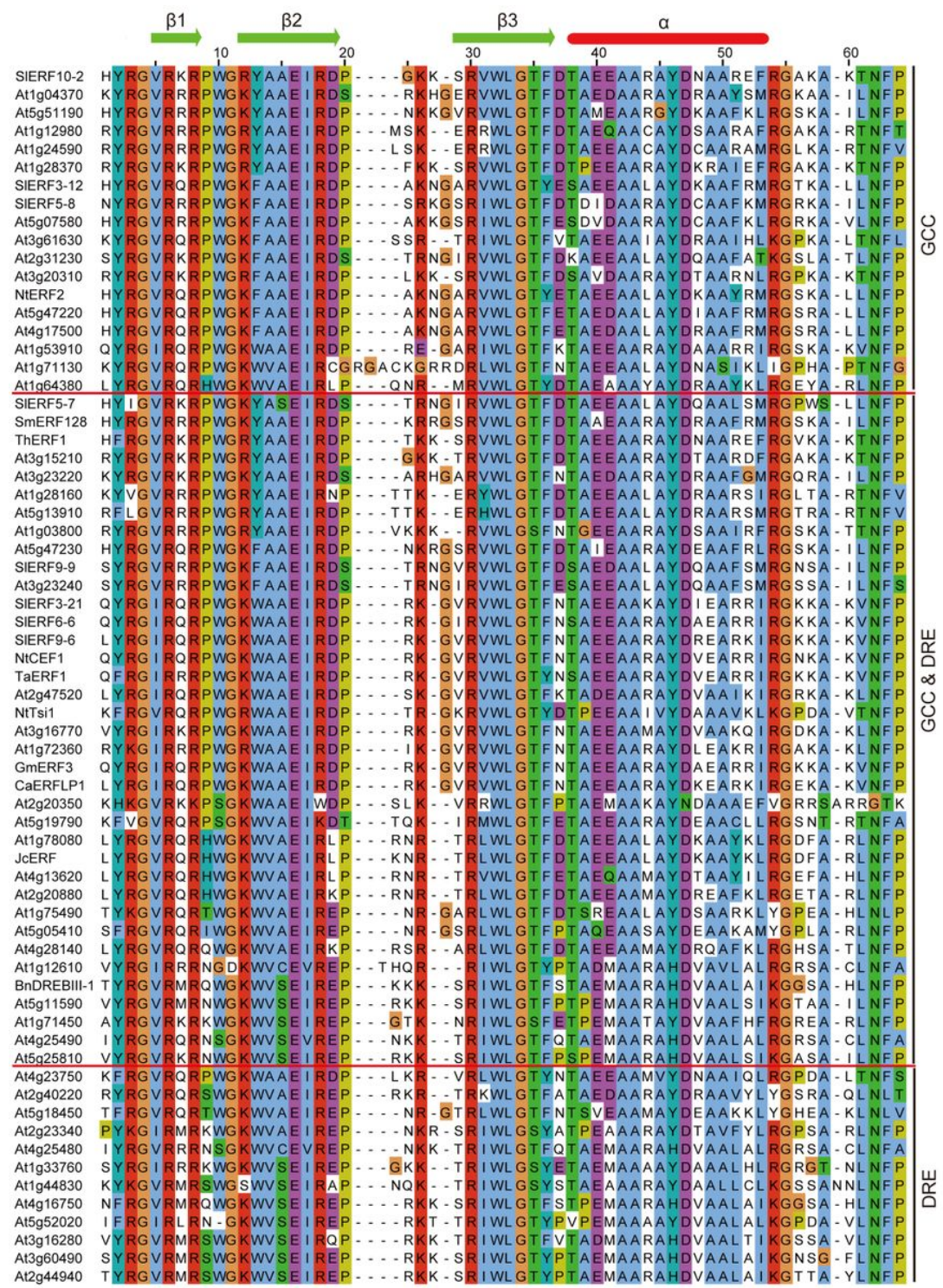

\section{Figure 3}

Comparison of the AP2 domain amino acid sequences of 49 Arabidopsis and 19 other species ERF proteins. SIERF10-2, SIERF3-12, SIERF5-8 [33]; At1g04370, At5g51190, At1g12980, At1g24590, At1g28370, At5g07580, At3g61630, At2g31230, At3g20310, At4g17500, At1g53910, At1g71130, At1g64380, At3g23220, At1g28160, At5g13910, At1g03800, At2g20350, At5g19790, At4g13620, At2g20880, At1g75490, At4g28140, At1g12610, At1g71450, At4g25490, At2g40220, At5g18450, At2g23340, At4g25480, At1g33760, At1g44830, At4g16750, At5g52020, At3g16280, At3g60490, At4g23750, and At2g44940 [34]; NtERF2 [35], At5g47220, At3g15210, At5g47230 [19], SIERF5-7 [36], SmERF128 [37], ThERF1 [38], SIERF9-9 [39], At3g23240 [40], SIERF3-21 [41], SIERF6-6 [42], SIERF9-6 [43], NtCEF1 [44], TaERF1 [45], At2g47520 [46], NtTsi1 [47], At3g16770 [48], At1g72360 [49], GmERF3 [50], CaERFLP1 [51], At1g78080 [52], JcERF [53], At5g05410 [11], BnDREBIII-1 [54], At5g11590 [55], At5g25810 [56]. 


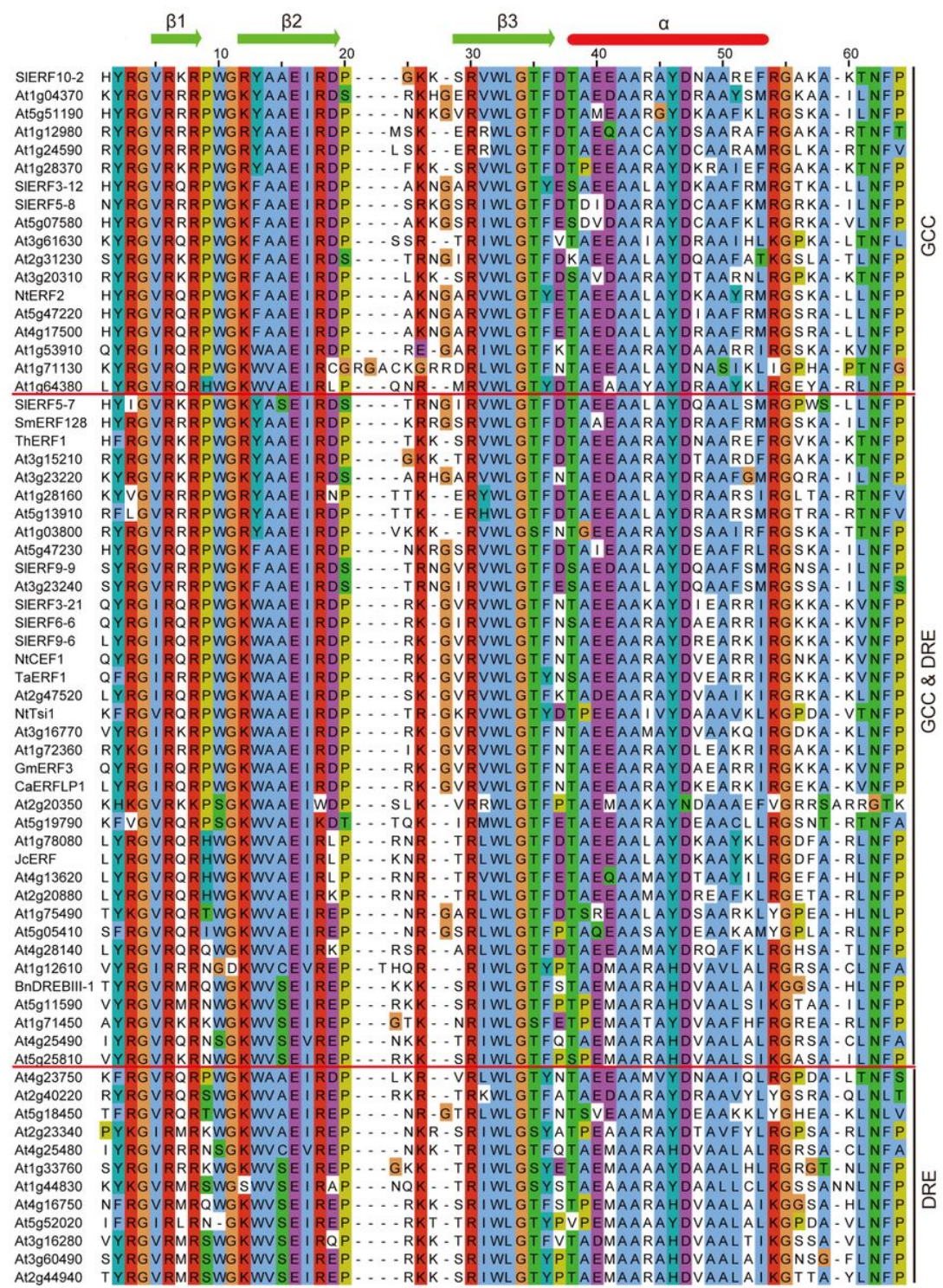

\section{Figure 3}

Comparison of the AP2 domain amino acid sequences of 49 Arabidopsis and 19 other species ERF proteins. SIERF10-2, SIERF3-12, SIERF5-8 [33]; At1g04370, At5g51190, At1g12980, At1g24590, At1g28370, At5g07580, At3g61630, At2g31230, At3g20310, At4g17500, At1g53910, At1g71130, At1g64380, At3g23220, At1g28160, At5g13910, At1g03800, At2g20350, At5g19790, At4g13620, At2g20880, At1g75490, At4g28140, At1g12610, At1g71450, At4g25490, At2g40220, At5g18450, At2g23340, At4g25480, At1g33760, At1g44830, At4g16750, At5g52020, At3g16280, At3g60490, At4g23750, and At2g44940 [34]; NtERF2 [35], At5g47220, At3g15210, At5g47230 [19], SIERF5-7 [36], SmERF128 [37], ThERF1 [38], SIERF9-9 [39], At3g23240 [40], SIERF3-21 [41], SIERF6-6 [42], SIERF9-6 [43], NtCEF1 [44], TaERF1 [45], At2g47520 [46], NtTsi1 [47], At3g16770 [48], At1g72360 [49], GmERF3 [50], CaERFLP1 [51], At1g78080 [52], JcERF [53], At5g05410 [11], BnDREBIII-1 [54], At5g11590 [55], At5g25810 [56]. 

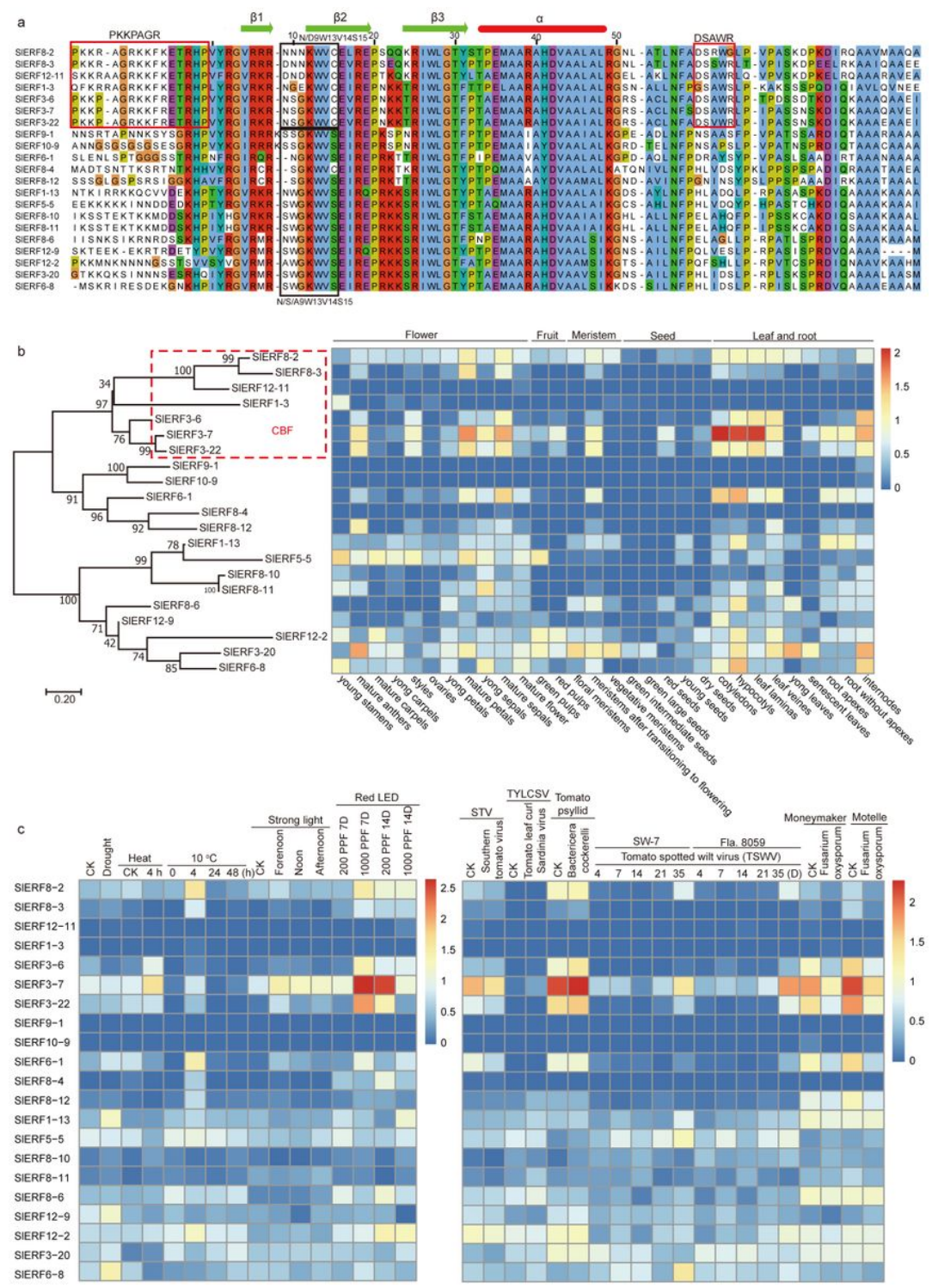

\section{Figure 4}

Expression levels of CBFs and their similar DREB genes in 30 tomato organs and under different biotic and abiotic stresses. (a), AP2 domain sequences comparison; ( $\mathrm{b}$ and $\mathrm{c}$ ), heatmap analysis of CBFs and their similar DREB based on TPM values in 30 tomato organs and under different biotic and abiotic stresses, respectively. TSWV, tomato spotted wilt virus; STV, southern tomato virus; TYLCSV, tomato leaf curl Sardinia virus. 

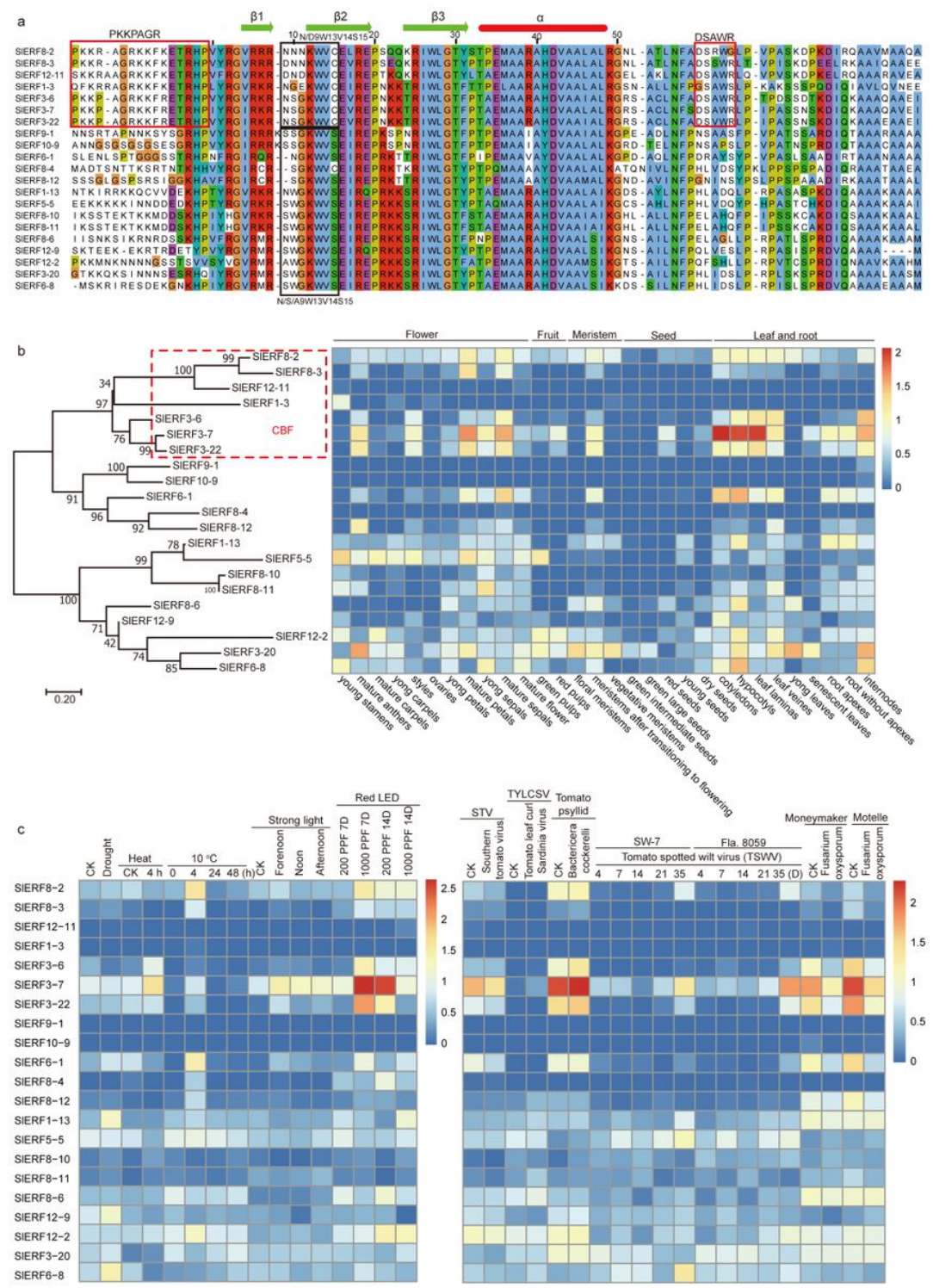

\section{Figure 4}

Expression levels of CBFs and their similar DREB genes in 30 tomato organs and under different biotic and abiotic stresses. (a), AP2 domain sequences comparison; ( $\mathrm{b}$ and $\mathrm{c}$ ), heatmap analysis of CBFs and their similar DREB based on TPM values in 30 tomato organs and under different biotic and abiotic stresses, respectively. TSWV, tomato spotted wilt virus; STV, southern tomato virus; TYLCSV, tomato leaf curl Sardinia virus. 


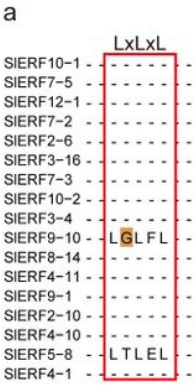

SIERF4-1
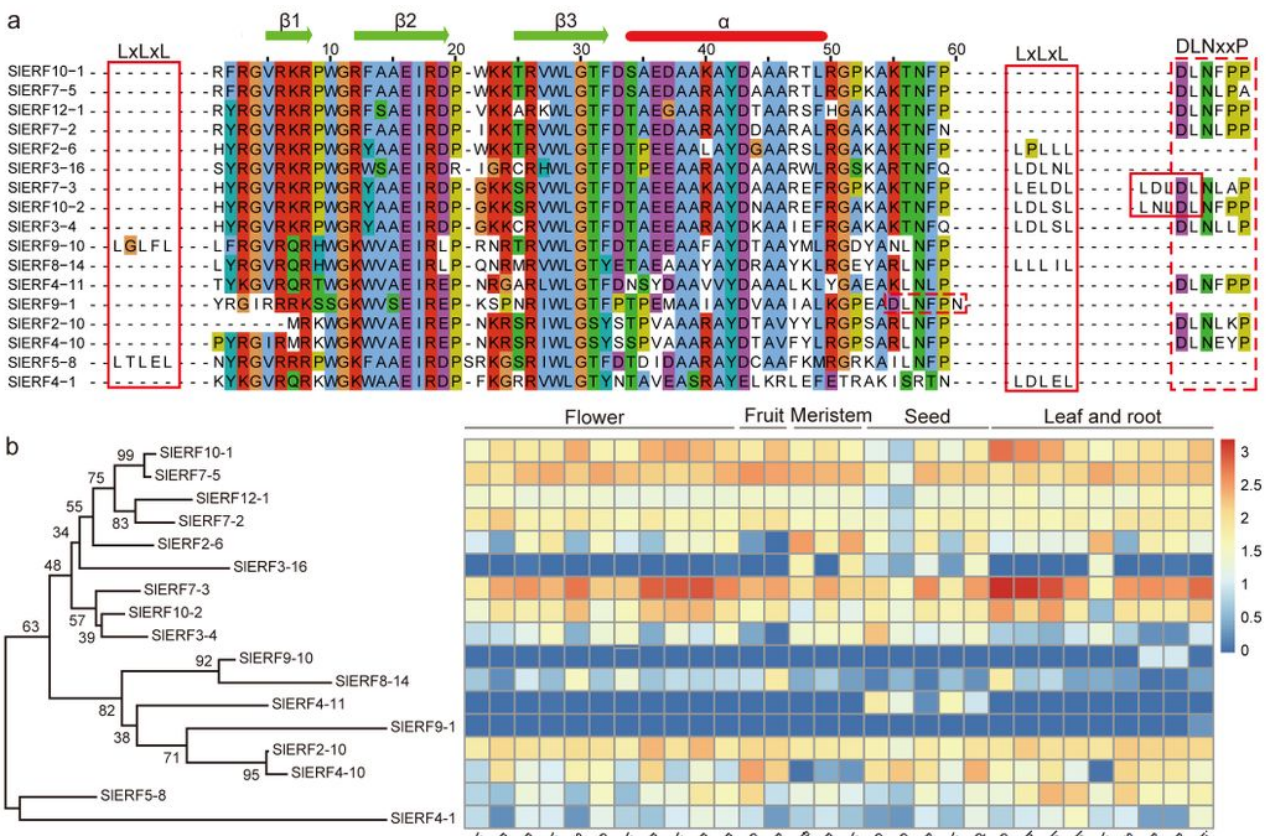

Flower

Fruit Meristem Seed

Leaf and root

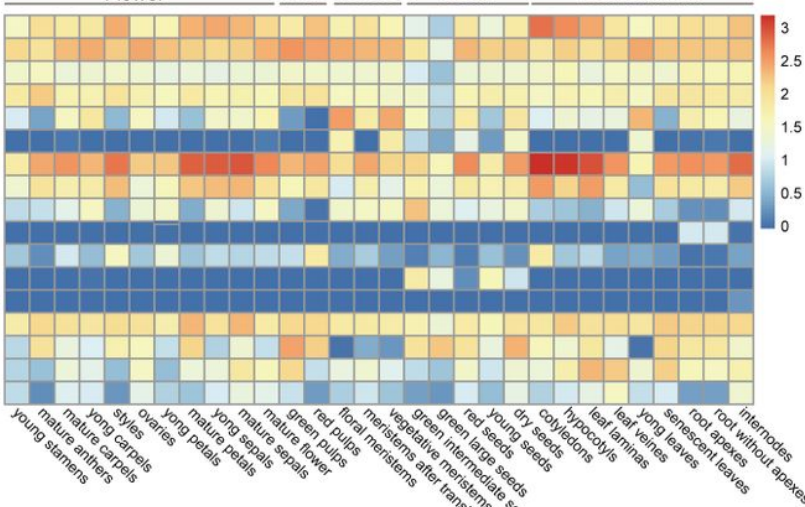

$\stackrel{\longmapsto}{0.20}$

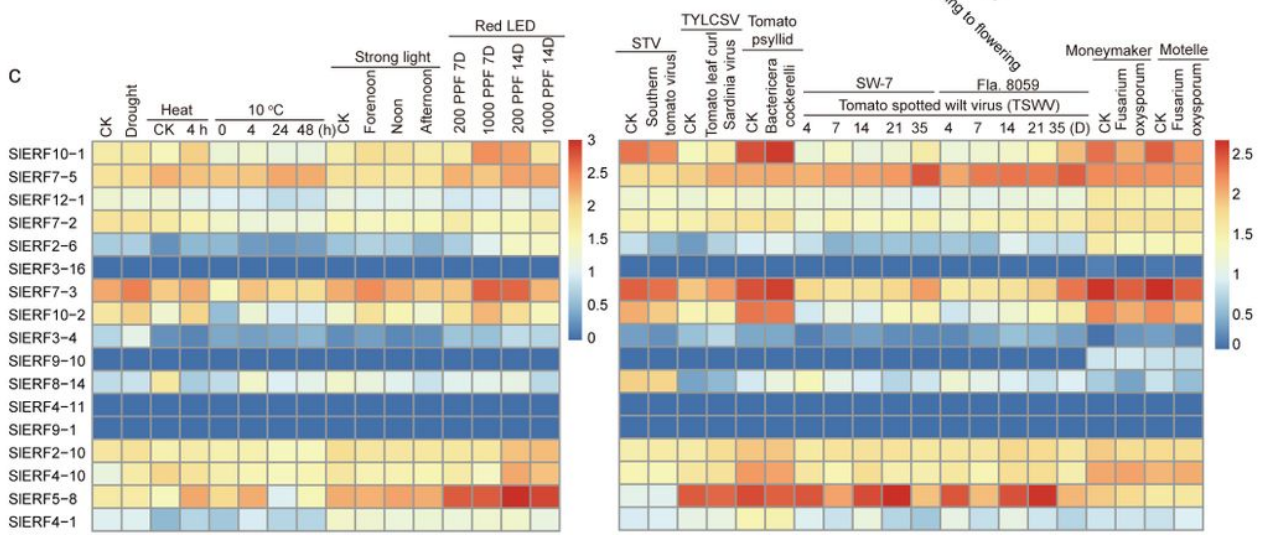

\section{Figure 5}

Expression levels of all repressor genes in 30 tomato organs and under different biotic and abiotic stresses. (a), AP2 domain sequences and EAR motifs analysis; ( $b$ and $c$ ), heatmap analysis of all repressor genes based on TPM values in 30 tomato organs and under different biotic and abiotic stresses, respectively. 


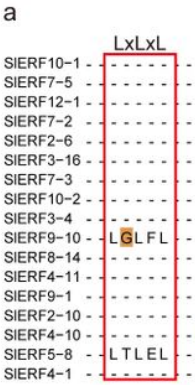

SIERF4-1
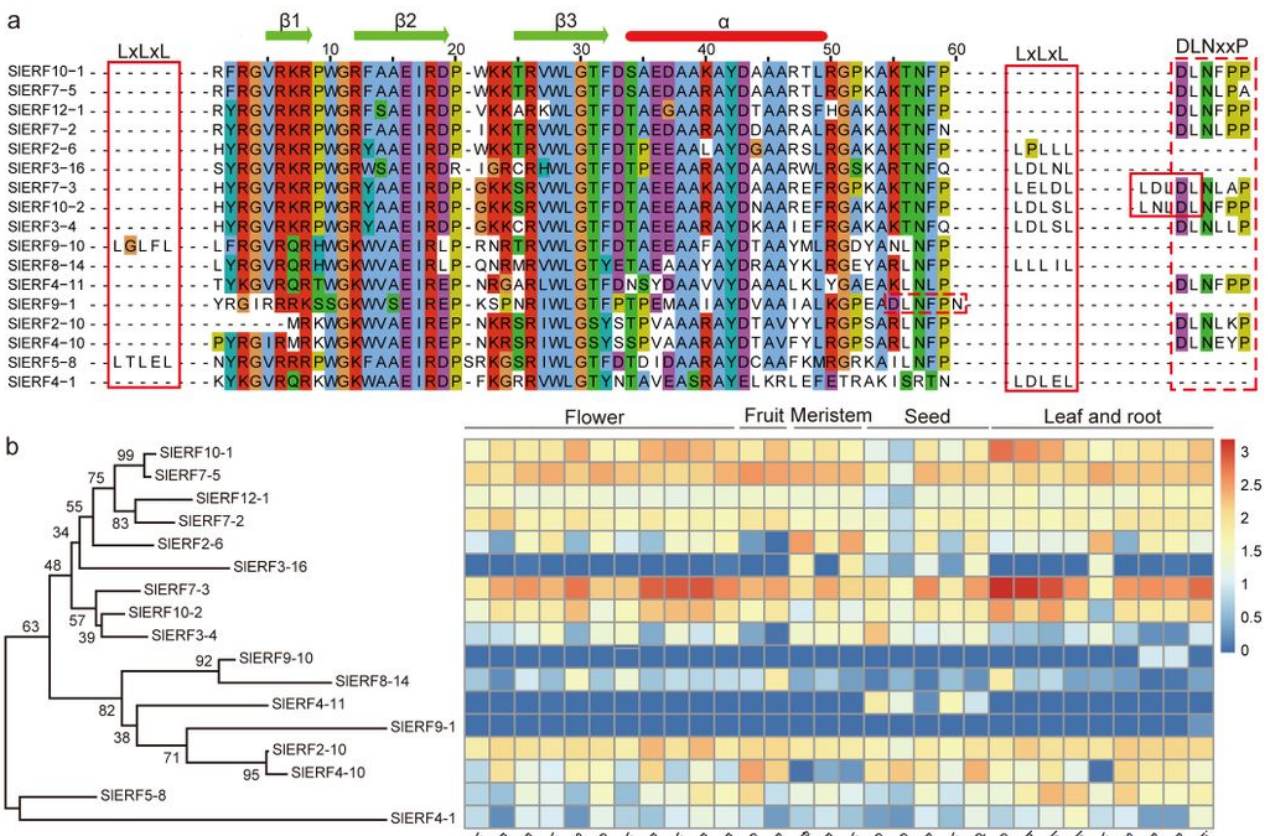

Flower

Fruit Meristem Seed

Leaf and root

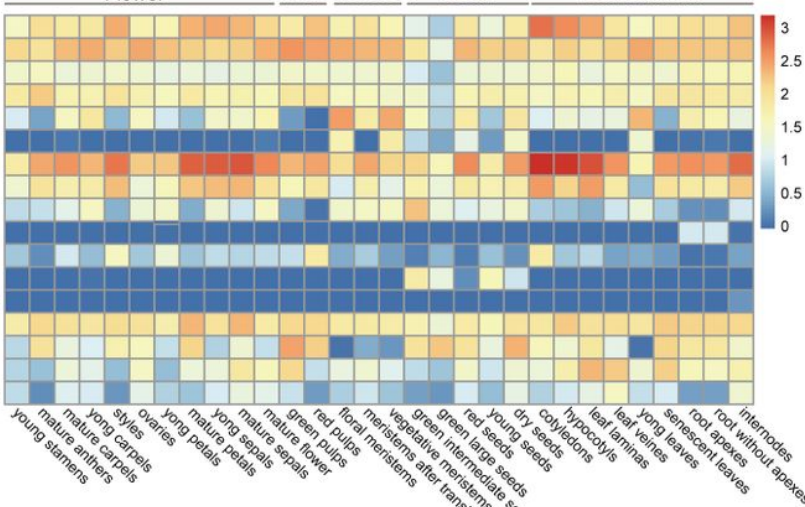

$\stackrel{\longmapsto}{0.20}$

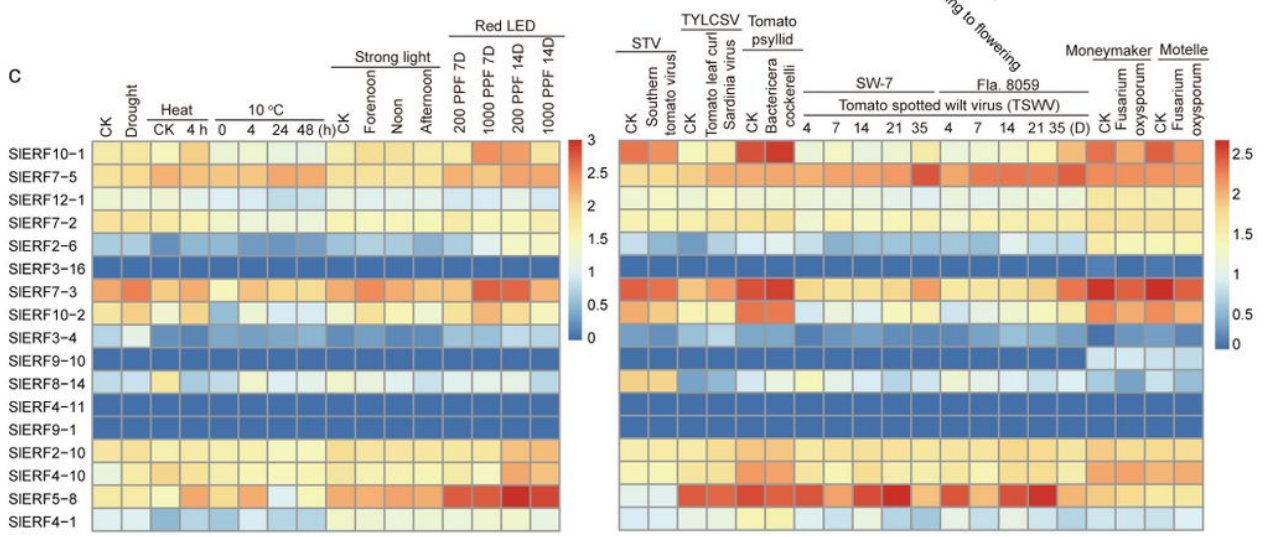

\section{Figure 5}

Expression levels of all repressor genes in 30 tomato organs and under different biotic and abiotic stresses. (a), AP2 domain sequences and EAR motifs analysis; ( $b$ and $c$ ), heatmap analysis of all repressor genes based on TPM values in 30 tomato organs and under different biotic and abiotic stresses, respectively. 

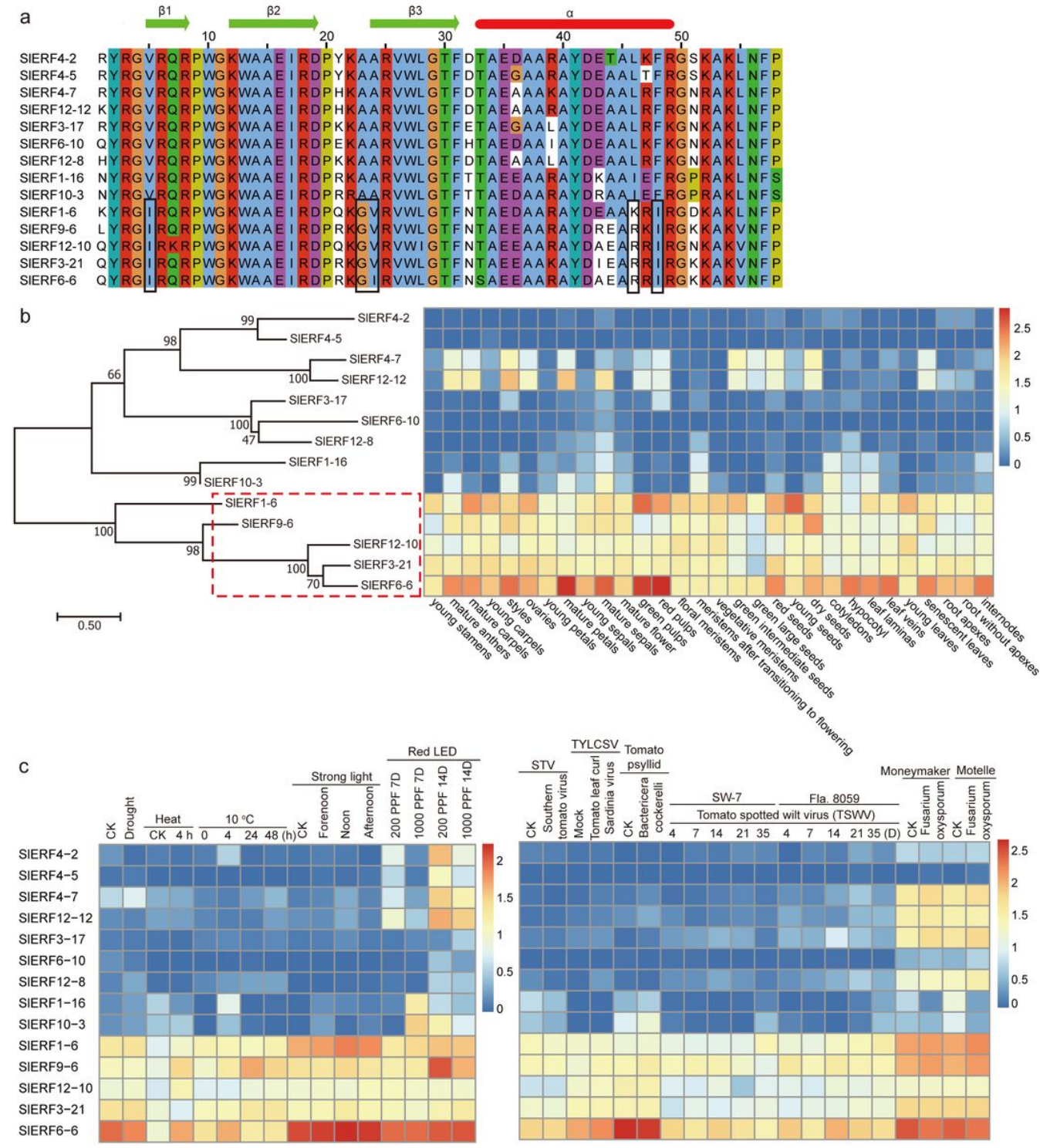

\section{Figure 6}

Expression levels of the $\triangle-A$ subgroup ERF genes in 30 tomato organs and under different biotic and abiotic stresses. (a), AP2 domain sequences comparison; ( $b$ and $c$ ), heatmap analysis of the $\bigotimes$-A subgroup ERF genes based on TPM values in 30 tomato organs and under different biotic and abiotic stresses, respectively. 

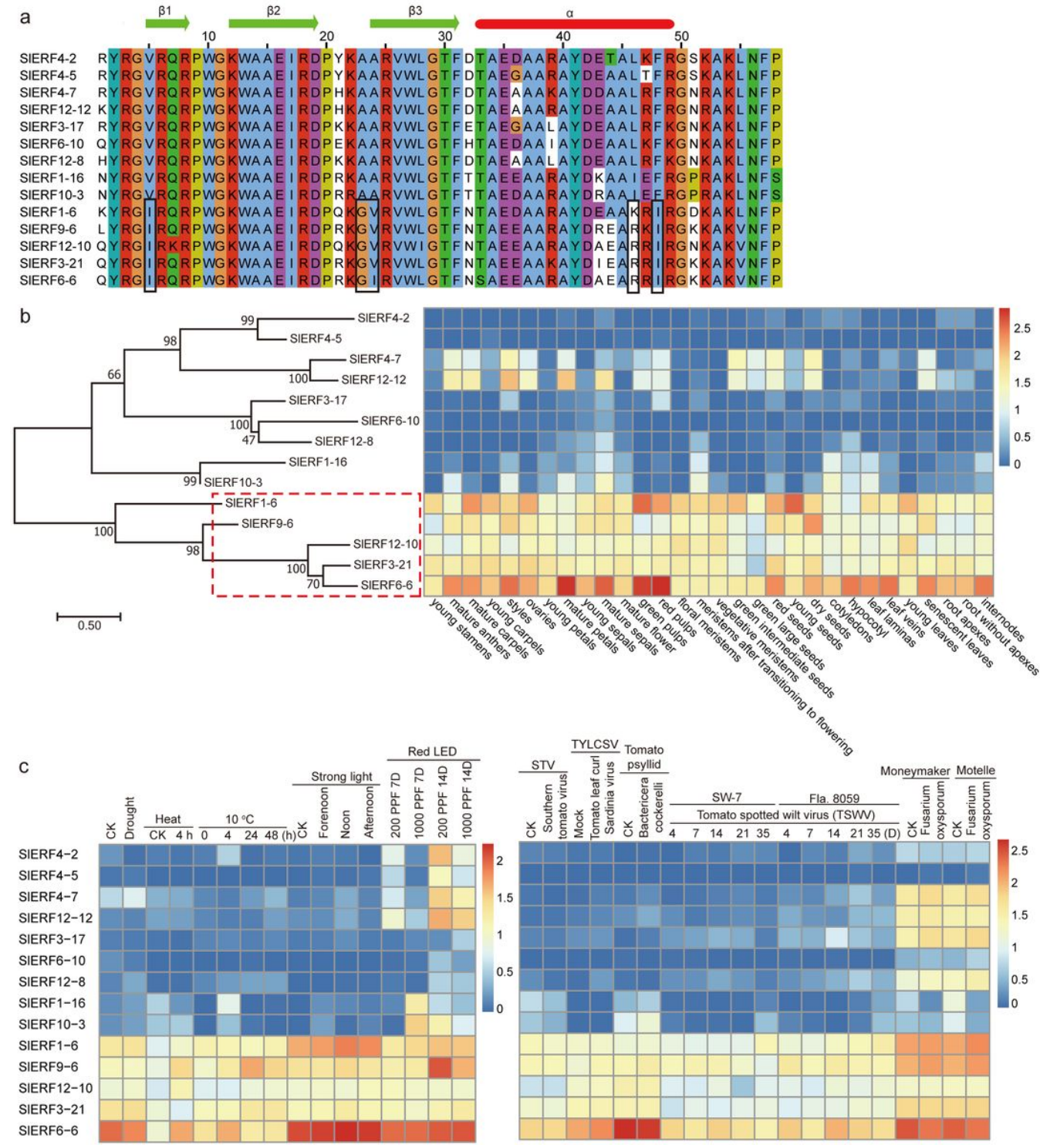

\section{Figure 6}

Expression levels of the $\triangle-A$ subgroup ERF genes in 30 tomato organs and under different biotic and abiotic stresses. (a), AP2 domain sequences comparison; ( $b$ and $c$ ), heatmap analysis of the $\bigotimes$-A subgroup ERF genes based on TPM values in 30 tomato organs and under different biotic and abiotic stresses, respectively. 


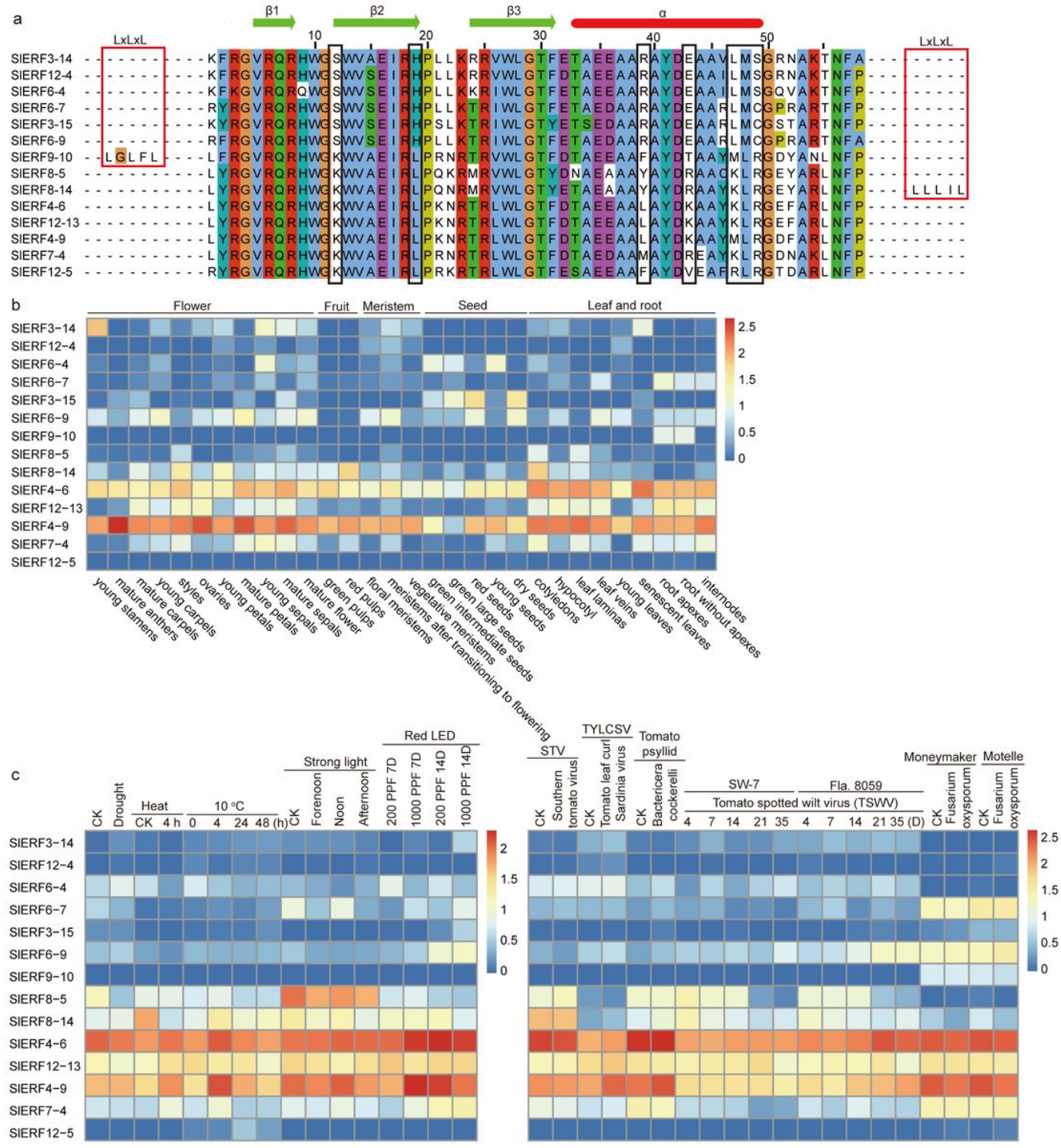

Figure 7

Expression levels of the $\mathbb{X}$-B subgroup DREB genes in 30 tomato organs and under different biotic and abiotic stresses.( a), AP2 domain sequences and EAR motifs analysis; ( $b$ and $c$ ), heatmap analysis of the $\mathbb{B}-B$ subgroup DREB genes based on TPM values in 30 tomato organs and under different biotic and abiotic stresses, respectively. 


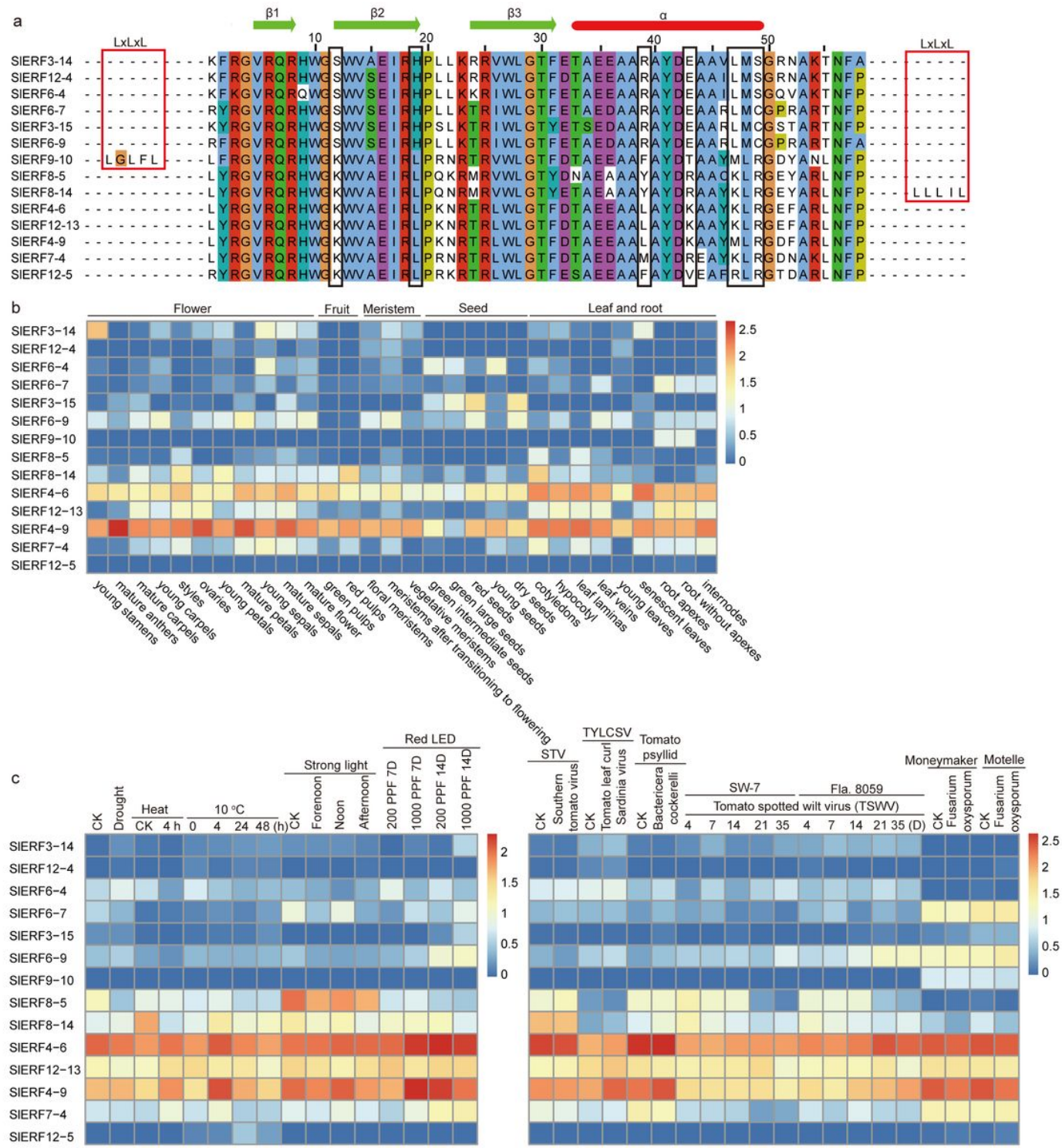

Figure 7

Expression levels of the $\mathbb{X}$-B subgroup DREB genes in 30 tomato organs and under different biotic and abiotic stresses.( a), AP2 domain sequences and EAR motifs analysis; ( $b$ and $c$ ), heatmap analysis of the $\mathbb{B}-B$ subgroup DREB genes based on TPM values in 30 tomato organs and under different biotic and abiotic stresses, respectively.

\section{Supplementary Files}

This is a list of supplementary files associated with this preprint. Click to download.

- Tables1.docx

- Tables1.docx

- Tables2.docx

- Tables2.docx

- Tables3.docx

- Tables3.docx

- Tables4.docx

- Tables4.docx

- Tables5.docx

- Tables5.docx 
- DataS1.xlsx

- DataS1.xIsx

- DataS2.xlsx

- DataS2.xIsx

- DataS3.xlsx

- DataS3.xIsx

- FigureS1.jpg

- FigureS1.jpg

- FigureS2.jpg

- Figures2.jpg 